\title{
JV TASK 119 - EFFECTS OF AGING ON TREATED ACTIVATED CARBONS
}

Final Report

(for the period of August 1, 2007 - June 30, 2009)

Prepared for:

AAD Document Control

U.S. Department of Energy

National Energy Technology Laboratory

626 Cochrans Mill Road

PO Box 10940, MS 921-107

Pittsburgh, PA 15236-0940

Cooperative Agreement: DE-FC26-98FT40321

Project Manager: Andrew O'Palko

Prepared by:

Edwin S. Olson Lucinda L. Hamre

John H. Pavlish Blaise A. Mibeck

Energy \& Environmental Research Center

University of North Dakota 15 North 23rd Street, Stop 9018

Grand Forks, ND 58202-9018 


\section{DOE DISCLAIMER}

This report was prepared as an account of work sponsored by an agency of the United States Government. Neither the United States Government, nor any agency thereof, nor any of their employees makes any warranty, express or implied, or assumes any legal liability or responsibility for the accuracy, completeness, or usefulness of any information, apparatus, product, or process disclosed or represents that its use would not infringe privately owned rights. Reference herein to any specific commercial product, process, or service by trade name, trademark, manufacturer, or otherwise does not necessarily constitute or imply its endorsement, recommendation, or favoring by the United States Government or any agency thereof. The views and opinions of authors expressed herein do not necessarily state or reflect those of the United States Government or any agency thereof.

\section{ACKNOWLEDGMENT}

This report was prepared with the support of the U.S. Department of Energy (DOE) National Energy Technology Laboratory Cooperative Agreement No. DE-FC26-98FT40321. However, any opinions, findings, conclusions, or recommendations expressed herein are those of the authors(s) and do not necessarily reflect the views of DOE.

\section{EERC DISCLAIMER}

LEGAL NOTICE This research report was prepared by the Energy \& Environmental Research Center (EERC), an agency of the University of North Dakota, as an account of work sponsored by DOE, the North Dakota Industrial Commission, the Electric Power Research Institute, Otter Tail Power Company, and SaskPower. Because of the research nature of the work performed, neither the EERC nor any of its employees makes any warranty, express or implied, or assumes any legal liability or responsibility for the accuracy, completeness, or usefulness of any information, apparatus, product, or process disclosed, or represents that its use would not infringe privately owned rights. Reference herein to any specific commercial product, process, or service by trade name, trademark, manufacturer, or otherwise does not necessarily constitute or imply its endorsement or recommendation by the EERC.

\section{NDIC DISCLAIMER}

This report was prepared by the EERC pursuant to an agreement partially funded by the Industrial Commission of North Dakota, and neither the EERC nor any of its subcontractors nor the North Dakota Industrial Commission nor any person acting on behalf of either:

(A) Makes any warranty or representation, express or implied, with respect to the accuracy, completeness, or usefulness of the information contained in this report, or that the use of any information, apparatus, method, or process disclosed in this report may not infringe privately owned rights; or 
(B) Assumes any liabilities with respect to the use of, or for damages resulting from the use of, any information, apparatus, method, or process disclosed in this report.

Reference herein to any specific commercial product, process, or service by trade name, trademark, manufacturer, or otherwise does not necessarily constitute or imply its endorsement, recommendation, or favoring by the North Dakota Industrial Commission. The views and opinions of authors expressed herein do not necessarily state or reflect those of the North Dakota Industrial Commission. 


\section{JV TASK 119 - EFFECTS OF AGING ON TREATED ACTIVATED CARBONS}

\section{PROJECT ABSTRACT}

For both the United States and Canada, testing has been under way for electric utilities to find viable and economical mercury control strategies to meet pending future mercury emission limits. The technology that holds the most promise for mercury control in low-chlorine lignite to meet the needs of the Clean Air Act in the United States and the Canada-Wide Standards in Canada is injection of treated activated carbon (AC) into the flue gas stream. Most of the treated carbons are reported to be halogenated, often with bromine.

Under a previous multiyear project headed by the Energy \& Environmental Research Center (EERC), testing was performed on a slipstream unit using actual lignite-derived flue gas to evaluate various sorbent technologies for their effectiveness, performance, and cost. Testing under this project showed that halogenated ACs performed very well, with mercury capture rates often $\geq 90 \%$. However, differences were noted between treated ACs with respect to reactivity and capacity, possibly as a result of storage conditions. Under certain conditions (primarily storage in ambient air), notable performance degradation had occurred in mercury capture efficiency. Therefore, a small exploratory task within this project evaluated possible differences resulting from storage conditions and subsequent effects of aging that might somehow alter their chemical or physical properties.

In order to further investigate this potential degradation of treated (halogenated) ACs, the EERC, together with DOE's National Energy Technology Laboratory, the North Dakota Industrial Commission (NDIC), the Electric Power Research Institute (EPRI), SaskPower, and Otter Tail Power Company, assessed the aging effects of brominated ACs for the effect that different storage durations, temperatures, and humidity conditions have on the mercury sorption capacity of treated ACs.

No aging effects on initial capture activity were observed for any carbons or conditions in the investigation. As measured by the $50 \%$ breakthrough time, no changes in capacity were observed for Norit LH samples stored frozen and likely none for Norit LH samples stored under high humidity conditions.

The major aging effects on capacity for the EERC brominated sample were seen as a decrease in capacity during the first week of storage under high humidity conditions. Storage of the Norit LH and the EERC 5\% brominated samples under low humidity conditions resulted in slightly improved capacities. Storage of the $15 \%$ brominated sample under high humidity conditions also improved the capacity.

Surface analysis using x-ray photoelectron spectroscopy (XPS) showed some migration of bromine to and from the surface occurred during storage, although no net loss of bromine was observed. The migration to the surface in the case of the $15 \%$ brominated carbon correlates with the increased capacity observed for this sample. The XPS elemental speciation data for the EERC brominated carbons showed a trend toward more bromide being formed at the expense of 
covalent bromine during storage. This was especially great for the $15 \%$ and the $5 \%$ stored in low humidity. The Norit LH samples did not show this increase in bromide concentration. This is consistent with the lack of change in capacity for the Norit LH during storage. The carbon speciation data showed generally more oxidization of carbon surfaces with storage, especially formation of carboxylate groups. The least increase in carboxylate groups was seen for the Norit LH stored under low humidity, which correlates with its increased capacity. In conclusion, the observed changes in surface chemistry can be related to the minimal changes in capacity observed, but the factors operate in different directions, so the relationships are complex.

High-quality x-ray absorption fine structure spectra were obtained for most of the samples. Significant changes were observed in the $\mathrm{x}$-ray absorption near edge structure and extended $\mathrm{x}$ ray absorption fine structure spectra of the stored carbons, but proved difficult to interpret and correlate with structural changes. 


\section{TABLE OF CONTENTS}

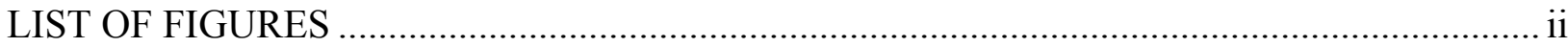

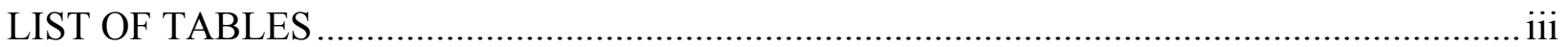

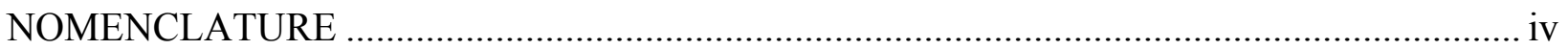

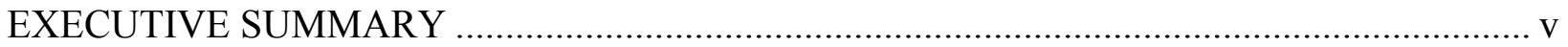

INTRODUCTION AND PROJECT DESCRIPTION …………................................................. 1

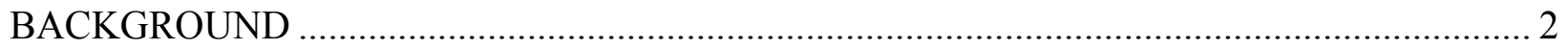

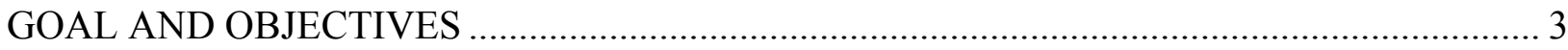

TESTING CONDUCTED UNDER PHASE II ................................................................. 3

TESTING APPROACH - EFFECTS OF AGING ON TREATED

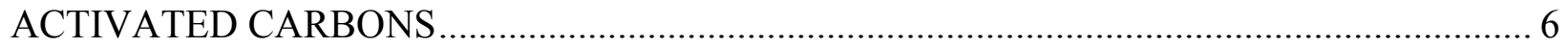

EERC Bench-Scale Mercury System and Test Procedure ................................................ 8

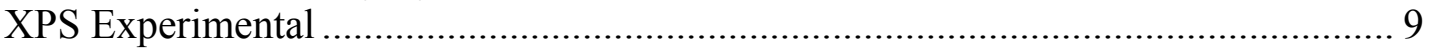

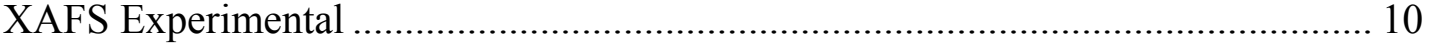

Quality Measures....................................................................................................... 10

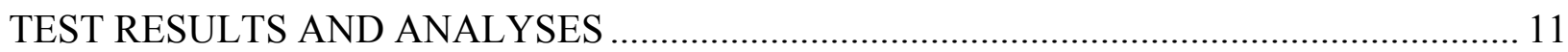

Bench-Scale Evaluations of Carbon Reactivity and Capacity ........................................... 13

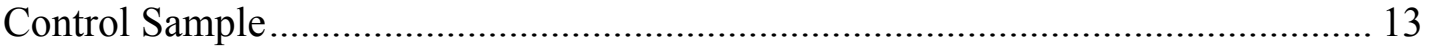

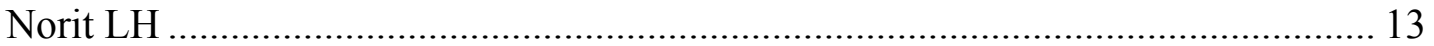

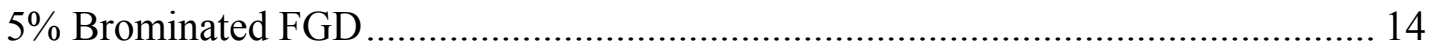

15\% Brominated FGD............................................................................... 15

Summary of Mercury Sorption Data ......................................................................... 15

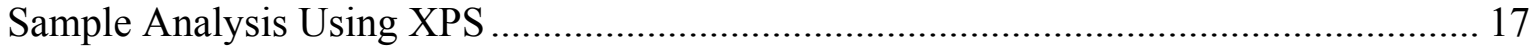

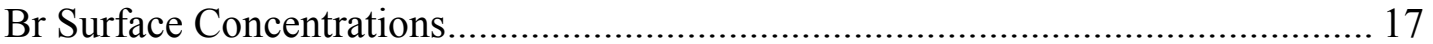

Correlation of Bromine Concentration Data with Carbon Capacity .......................... 18

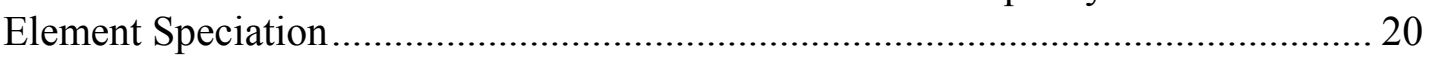

Correlation of Carbon Speciation with 50\% Breakthrough ..................................... 21

Correlation of Bromine Speciation Results with Mercury Capacity.......................... 24

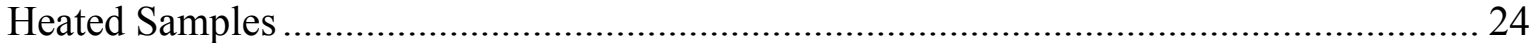

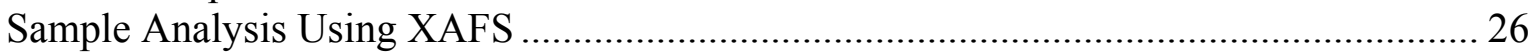

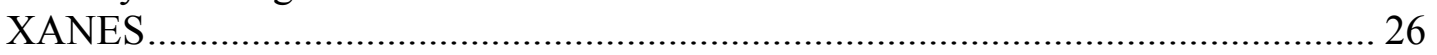

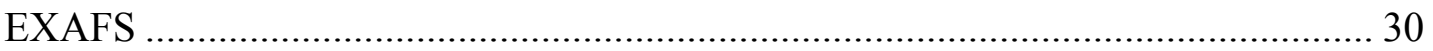

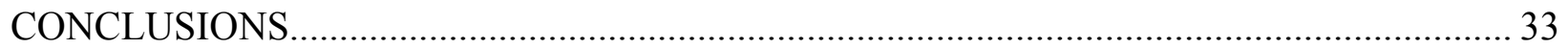

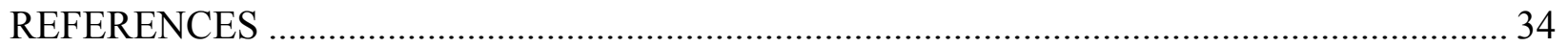




\section{LIST OF FIGURES}

1 Aging chambers with temperature- and relative humidity-controlled environment ............. 7

2 Schematic of EERC bench-scale apparatus .................................................................... 9

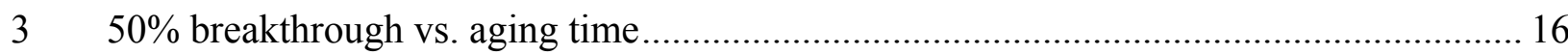

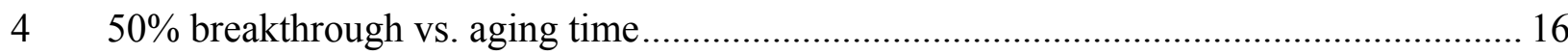

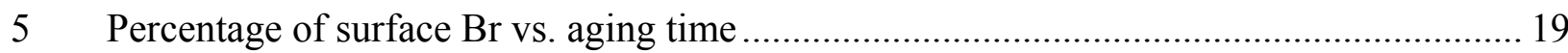

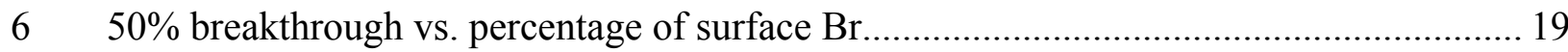

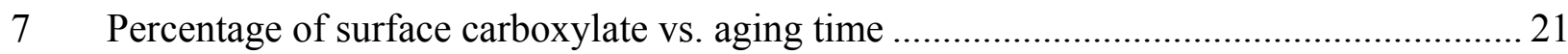

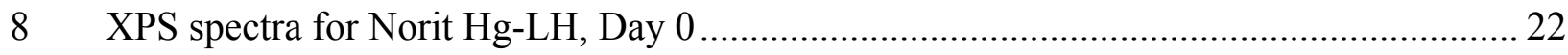

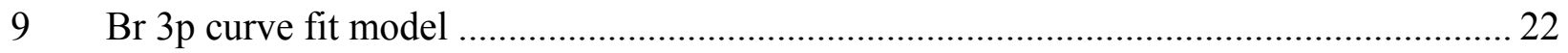

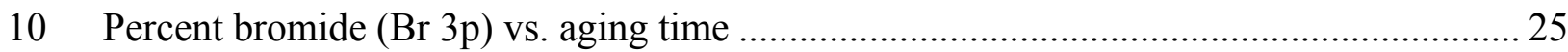

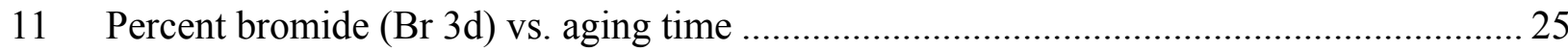

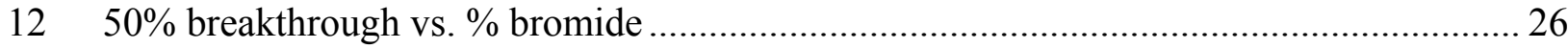

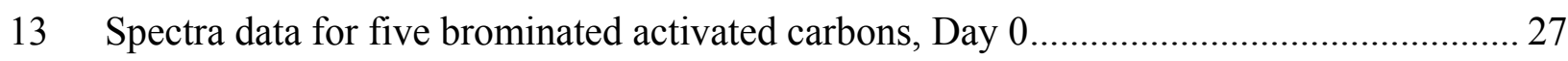

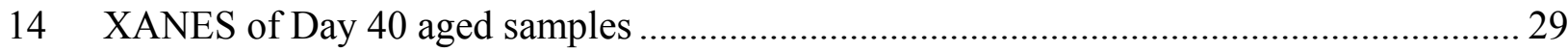

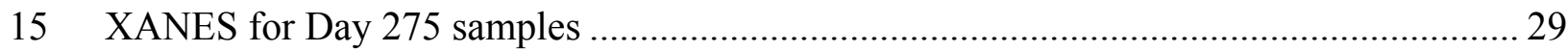

16 EXAFS/RSF data for Day 0 sample and heated samples................................................. 31

17 The bromine-carbon structure that is determined from the first two peaks of the EXAFS/RSF data produced by Dr. Huggins..................................................................... 31

18 The bromine-carbon structure is further defined by looking at the third EXAFS peak, suggesting that the bromine atoms are bound to a rigid structure, possibly a benzene ring ………………………………................................................ 32

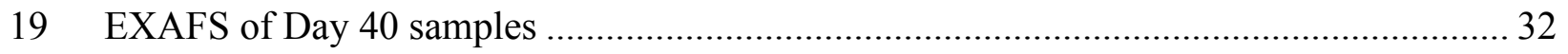

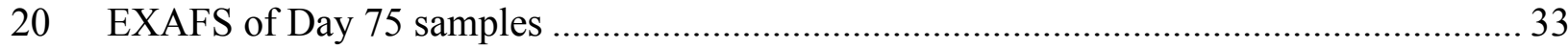




\section{LIST OF TABLES}

1 Bench-Scale Results for Freshly Brominated Sorbents ............................................. 5

2 Bench-Scale Results for Suite of Sorbents.................................................................. 5

3 Bench-Scale Results for Best Sorbent .................................................................... 5

$4 \quad$ Flue Gas Constituents for Test Conditions ............................................................. 8

$5 \quad 50 \%$ Breakthrough Times for Brominated Samples under Low Acid Gas Conditions ......................................................................................... 14

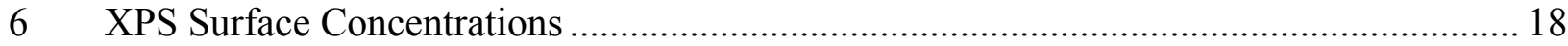

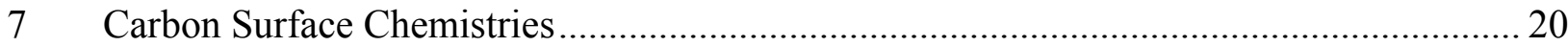

8 Bromine Surface Chemistries for Brominated Samples …......................................... 23

9 Bromine Surface Chemistries for Brominated Samples .............................................. 24

10 Spectral Changes for Initial and Stored Samples .................................................... 28 


\section{NOMENCLATURE}

AC activated carbon

ACI activated carbon injection

CATM $^{\circledR} \quad$ Center for Air Toxic Metals ${ }^{\circledR}$ (at the EERC)

CMM continuous mercury monitor

$\mathrm{DE} \quad$ diatomaceous earth

DOE U.S. Department of Energy

EERC Energy \& Environmental Research Center

ECRF Emission Control Research Facility (at SaskPower's Poplar River Station)

EPRI Electric Power Research Institute

ESP electrostatic precipitator

NDIC North Dakota Industrial Commission

NSLS National Synchrotron Light Source

RH relative humidity

RSF radial structure function

XAFS $\quad \mathrm{x}$-ray absorption fine structure

XANES $\quad \mathrm{x}$-ray absorption near edge structure

XPS $\quad$ X-ray photoelectron spectroscopy 


\section{JV TASK 119 - EFFECTS OF AGING ON TREATED ACTIVATED CARBONS}

\section{EXECUTIVE SUMMARY}

For both the United States and Canada, testing has been under way for electric utilities to find viable and economical mercury control strategies to meet pending future mercury emission limits. The technology that holds the most promise for mercury control in low-chlorine lignite to meet the needs of the Clean Air Act in the United States and the Canada-Wide Standards in Canada is injection of treated activated carbon (AC) into the flue gas stream. Many of the treated carbons are halogenated, often with bromine.

Under a previous two-phase, multiyear consortium project headed by the Energy \& Environmental Research Center (EERC) in conjunction with several North Dakota utilities, SaskPower, the U.S. Department of Energy (DOE), the Electric Power Research Institute (EPRI), and the North Dakota Industrial Commission (NDIC), as well as several Canadian entities, testing was performed on a slipstream unit at SaskPower's Poplar River Station's Emission Control Research Facility to evaluate various sorbent technologies for their effectiveness, performance, and cost. Testing under this project showed that halogenated ACs performed very well, with mercury capture rates often $\geq 90 \%$. However, differences were noted between treated ACs with respect to reactivity and capacity, possibly as a result of storage conditions. Under certain conditions (primarily storage in ambient air), notable performance degradation occurred in mercury capture efficiency. Therefore, a small exploratory task within this project evaluated possible differences resulting from storage conditions and subsequent effects of aging that might somehow alter their chemical or physical properties.

In order to further investigate this potential degradation of treated (halogenated) ACs, the EERC, together with support from DOE's National Energy Technology Laboratory, NDIC, EPRI, SaskPower, Otter Tail Power Company, and the Center for Air Toxic Metals ${ }^{\circledR}\left(\mathrm{CATM}^{\circledR}\right)$, assessed the aging effects of brominated ACs for the effect that different storage durations, temperatures, and humidity conditions have on the mercury sorption capacity of treated ACs.

A chamber was constructed to allow carbons to be stored in a clean environment, with varied temperatures and humidity levels. These were tested against a control batch of commercial ACs that has been stored under controlled conditions and shown to be stable for a number of years. After aging each under various conditions, the carbons were tested for mercury reactivity and capacity on a bench-scale mercury test system at the EERC, which has been used for evaluating many hundreds of sorbents in a simulated flue gas (homogeneous) with gaseous mixtures typical of those seen in actual combustion environments. Select carbons were also analyzed using $\mathrm{x}$-ray photoelectron spectroscopy (XPS) and x-ray absorption fine structure (XAFS).

The major aging effects were seen after storage for a relatively short period of time; the greatest change in mercury capacity was seen between product creation (Baseline or Day 0) and approximately 1 week. After this period, it does not appear that major changes occur. Chemical 
analysis does reflect changes in the bromine on the carbon, but it was beyond the scope of this project to determine how that might affect changes at a more fundamental level.

No aging effects on initial capture activity were observed for any carbons or conditions in the investigation. As measured by the $50 \%$ breakthrough time, no changes in capacity were observed for Norit LH samples stored frozen and likely none for Norit LH samples stored under high humidity conditions. The major aging effects on capacity for the EERC brominated sample were seen as a decrease in capacity during the first week of storage under high humidity conditions. Storage of the Norit LH and the EERC 5\% brominated samples under low humidity conditions resulted in slightly improved capacities. Storage of the $15 \%$ brominated sample under high humidity conditions also improved the capacity.

Surface analysis using XPS showed that some migration of bromine to and from the surface occurred during storage, although no net loss of bromine was observed. The migration to the surface in the case of the $15 \%$ brominated carbon correlates with the increased capacity observed for this sample. The XPS elemental speciation data for the EERC brominated carbons showed a trend toward more bromide being formed at the expense of covalent bromine during storage. This was especially great for the $15 \%$ and the $5 \%$ stored in low humidity. The Norit LH samples did not show this increase in bromide concentration. This is consistent with the lack of change in capacity for the Norit LH during storage. The carbon speciation data showed generally more oxidization of carbon surfaces with storage, especially formation of carboxylate groups. The least increase in carboxylate groups was seen for the Norit LH stored under low humidity, which correlates with its increased capacity. In conclusion, the observed changes in surface chemistry could be related to the minimal changes in capacity observed, but the factors affect the results in different directions, so the relationships are complex.

High-quality XAFS spectra were obtained for most of the samples. Significant changes were observed in the x-ray absorption near-edge structure and extended x-ray absorption fine structure spectra of the stored carbons, but proved difficult to interpret and correlate with structural changes. 


\section{JV TASK 119 - EFFECTS OF AGING ON TREATED ACTIVATED CARBONS}

\section{INTRODUCTION AND PROJECT DESCRIPTION}

In the past, low-chlorine coals were considered to be the most problematic and challenging for mercury control. However, treated activated carbons (ACs) (including those that are halogenated by bromine) have shown good to excellent mercury capture for lignite-derived flue gas. For lignite-fired utilities in the United States and Canada to effectively and economically meet the requirements of the Clear Air Mercury Rule and the Canada-Wide Standards, respectfully, mercury control measures must be effective for various configurations and be consistent in performance.

For the last 5 years, the Energy \& Environmental Research Center (EERC) has undertaken a two-phase consortium project to pilot- and field-test various sorbents for mercury control that are applicable to utilities burning lignite coal. Phase I identified a limited number of lignitederived ACs, which were further tested at a larger scale for their ability to capture mercury. Activities are complete for Phase I, and a final report was issued in 2003.

Under Phase II, results from Phase I were used to launch testing on a slipstream unit at the SaskPower Poplar River Station Emission Control Research Facility (ECRF), which draws actual flue gas from either Unit 1 or 2 and provides it to the test equipment. This project was conducted by a consortium headed by the EERC that consisted of SaskPower, the U.S. Department of Energy (DOE), the Electric Power Research Institute, the North Dakota Industrial Commission (NDIC), and several North Dakota and Canadian entities. The Phase II final report was submitted to sponsors in May 2007.

During activities for Phase II, the primary focus was on the evaluation of sorbent-based technologies in a COHPAC ${ }^{\mathrm{TM}}$ system with $\mathrm{AC}$ injection (ACI) between the two control devices (known as a TOXECON ${ }^{\mathrm{TM}}$ arrangement in the United States) as the most effective means of controlling mercury without negatively affecting the fly ash at SaskPower's Poplar River Station. Most of the tests involved injection of AC upstream of a slipstream baghouse into actual flue gas that was drawn downstream of the Unit 1 or 2 electrostatic precipitators (ESPs).

Several brominated carbons were tested in this phase and compared to Luscar and Norit DARCO $^{\circledR} \mathrm{Hg}$ ACs. Results showed that treated (halogenated) ACs performed very well, with mercury capture rates often $\geq 90 \%$ (1). However, there were unexplained differences between brominated ACs with respect to reactivity and capacity, so a small suite of tests was initiated to allow a more in-depth evaluation to address possible differences resulting from storage conditions of treated carbons and subsequent effects of aging that might somehow alter their chemical or physical properties, making them less effective toward mercury capture.

Preliminary results showed that under certain conditions (primarily storage in ambient air), notable performance efficiencies decreased with regard to mercury capture. Although very small in scope, the outcomes of those bench-scale tests indicated the need for further evaluation, leading to this collaborative effort. 
Also, lignite-derived ACs, including those from Fort Union coals, have shown tremendous commercialization promise; it is, therefore, important to know the effects of halogenation on any new ACs that are being produced to meet the urgent market needs of lignite-fired utilities so that production, transportation, shipment, delivery, and on-site storage issues are well understood, with potential negative effects minimized. This project will address issues associated with aging and storage of treated ACs and will provide data to minimize uncertainties associated with applying treated sorbents for mercury control.

Several economic analyses have shown that the cost of the $\mathrm{AC}$ is the largest ongoing factor when ACI is used as a mercury control strategy. While cost estimates for mercury removal on a per-pound basis have been adjusted down significantly over the last 5 years, the cost of carbon still remains the greatest expenditure and thus must be optimized if at all possible.

\section{BACKGROUND}

Of the mercury control measures that are commercially available, sorbent injection, particularly of treated ACs, has shown the most promise for economical reduction of mercury emissions (1-3). However, the potential negative aspects of sorbent injection, whether they involve balance-of-plant impacts or the stability of $\mathrm{AC}$, merit further investigation so that optimal performance can be ensured, resulting in less uncertainty associated with implementing the technology.

During Phase II testing activities on the ECRF noted earlier, team members evaluated various sorbent technologies for their effectiveness, performance, and cost. The project showed that treated (halogenated) ACs performed very well, with mercury capture rates that sometimes exceeded $90 \%$. Treated ACs, in general, provide levels of capture in low-chlorine lignites that are not achievable using plain or untreated ACs (4-8). Many of the treated ACs are impregnated with various bromine compounds. It was expected that all of these brominated ACs would perform better than nontreated AC and behave similarly with respect to reactivity and capacity for mercury capture, but this was not borne out in testing (4). Reactivity is of significant concern when carbons are to be used in environments with short residence times, such as when injected upstream of an ESP. Capacity is a measure of the maximum amount of mercury that can be sorbed by the sorbent and is of critical importance in fixed-bed or baghouse applications.

Noting these performance differences, the EERC postulated that perhaps there were differences in how the various treated ACs were handled and stored, which subsequently may have introduced an aging effect that altered chemical or physical properties, making the ACs less effective at mercury capture.

To address these concerns, a small exploratory task was initiated under Phase II activities. For this limited testing, the project team determined the following objectives:

- Determine the effects of storage conditions on halogenated AC performance, as measured by mercury capture efficiency. 
- Evaluate both the reactivity and capacity of the carbons using an established EERC bench-scale system to control for flue gas constituents and temperature.

- Determine the speciation and loss of bromine using x-ray photoelectron spectroscopy (XPS).

- Eliminate unknown aging effects by producing fresh ACs by various treatment methods.

\section{GOAL AND OBJECTIVES}

The goal of this project was to address a data gap concerning storage modes on the effectiveness of treated (brominated) ACs. To date, outside of the small effort initiated by the EERC under Phase II activities, little to no testing has been done to test the stability of treated (halogenated) ACs when stored for different periods of time under different ambient conditions, which are typical and varied across North America. Using the EERC's bench-scale mercury testing system, the EERC evaluated the effect that different storage durations, temperatures, and humidity conditions had on the mercury sorption capacity of treated ACs.

During discussions with project members, key variables were identified as important and needing further evaluation. Specific objectives for this project were to obtain data sufficient to address the concerns mentioned below:

- Evaluate the effect of storage time on the change in mercury capture effectiveness.

- Evaluate the impact of storage humidity on treated AC performance.

- Evaluate the impact of storage temperature on treated ACs.

- Evaluate the impact of bromine concentration under varying storage conditions.

- Evaluate how varying storage conditions impact AC mercury capture under both high and low acid gas conditions.

- Determine if storage conditions affect the AC surface structure, surface area, or reactivity to capture mercury.

- Determine if reactivity of $\mathrm{AC}$ correlates to a change in the $\mathrm{Br}$ concentration or form.

\section{TESTING CONDUCTED UNDER PHASE II}

Since there are several potential methods for impregnation of bromine into AC, treated carbons were prepared in several ways and stored under several identical conditions to determine if carbons prepared differently would behave the same way if stored in like manner. To control 
for possible differences in the development, production, and shipment of commercially treated $\mathrm{AC}$ and that differences were not merely artifacts of the method of commercial production, a fresh supply of standard AC (Norit DARCO $\mathrm{Hg}$ ) was used and treated with bromine in the laboratory by aqueous and gaseous impregnation using four different methods:

- $\mathrm{AC}$ treatment with 5\% gaseous elemental bromine

- AC treatment with a gaseous bromine that was later vacuum-dried

- An AC that was treated with aqueous bromine

- A carbon that was treated with elemental bromine at an elevated temperature

These sorbent samples were all compared to a Norit DARCO Hg standard AC (untreated), which provides the largest control set of data of any commercial carbon available. Fresh AC batches were divided and subjected to different storage conditions for 90 days and then retested against the performance of the freshly prepared ACs. The storage conditions used under Phase II were as follows:

- Ambient air with uncontrolled moisture

- $\mathrm{N}_{2}$ at $25^{\circ} \mathrm{F}$

- $\mathrm{N}_{2}$ at $25^{\circ} \mathrm{C}$

- Dry air at $25^{\circ} \mathrm{C}$

- Untreated carbon stored in $\mathrm{N}_{2}$ at $25^{\circ} \mathrm{C}$ (control sample)

The EERC's bench-scale mercury system using simulated flue gas was used to evaluate initial reactivity and the capacity of the treated ACs that had been stored as noted above. Structural features were investigated using XPS of initial and stored samples to determine changes in the chemical associations of carbon, oxygen, sulfur, chlorine, and bromine at the sorbent surface.

Table 1 shows the results of testing the freshly prepared carbons for reactivity and capacity on the EERC bench-scale system. As can be seen from this table, no induction time (Columns 2 and 3) was required for the freshly treated carbons, showing immediate complete reactivity with the mercury in the gas stream. Breakthrough time (Column 4), an indication of mercury capacity, was twice that of the standard carbon control. Despite different methods of preparation (Column 1), speciation was similar for all of the samples, except for the vacuum-dried carbon.

Table 2 shows the comparison between the initial treated AC response times (shown in Table 1) to those obtained 90 days later for the sorbent samples stored under nitrogen. As seen from the table, irrespective of the preparation method, the initial reactivity was not affected. In each case, storage in ambient conditions (Table 3) resulted in a shorter breakthrough time, showing decreased capacity for mercury sorption. 
Table 1. Bench-Scale Results for Freshly Brominated Sorbents

\begin{tabular}{lcccc}
\hline Bromination Method & $\begin{array}{c}\text { Initial, } \\
\text { \% of inlet }\end{array}$ & $\begin{array}{c}\text { Induction, } \\
\text { minutes }\end{array}$ & $\begin{array}{c}50 \% \text { Breakthrough, } \\
\text { minutes }\end{array}$ & $\begin{array}{c}\text { Bromide } \\
\text { Concentration, \% }\end{array}$ \\
\hline $\begin{array}{l}\text { Gaseous } \mathrm{Br}_{2}, 25^{\circ} \mathrm{C} \\
\text { Gaseous } \mathrm{Br}_{2}, 25^{\circ} \mathrm{C},\end{array}$ & 0 & 0 & 48 & 77 \\
$\quad 2$ & 0 & 46 & 58 \\
Using $\mathrm{Vacuum}_{2}$-Dried AC & & & & \\
Aqueous $\mathrm{Br}_{2}, 25^{\circ} \mathrm{C}$ & 5 & 0 & 38 & 81 \\
${\mathrm{Gaseous} \mathrm{Br}_{2}, 60^{\circ} \mathrm{C}}_{\mathrm{No} \mathrm{Br}_{2} \text { Control }}^{2}$ & 47 & 0 & 46 & 79 \\
\hline
\end{tabular}

Table 2. Bench-Scale Results for Suite of Sorbents, stored 90 days in $\mathbf{N}_{2}$ at $25^{\circ} \mathrm{C}$

\begin{tabular}{lcccc}
\hline Bromination Method & $\begin{array}{c}\text { Initial, \% } \\
\text { of inlet }\end{array}$ & $\begin{array}{c}\text { Induction, } \\
\text { minutes }\end{array}$ & $\begin{array}{c}50 \% \text { Breakthrough, } \\
\text { minutes }\end{array}$ & $\begin{array}{c}\text { Bromide } \\
\text { Concentration, \% }\end{array}$ \\
\hline Gaseous $\mathrm{Br}_{2}, 25^{\circ} \mathrm{C}$ & 2 & 0 & 45 & 85 \\
Gaseous $\mathrm{Br}_{2}, 25^{\circ} \mathrm{C}$, & 2 & 0 & 32 & 69 \\
Using $\mathrm{Vacuum}^{-\mathrm{Dried} A C}$ & & & & \\
Aqueous $\mathrm{Br}_{2}, 25^{\circ} \mathrm{C}$ & 3 & 0 & 30 & 82 \\
Gaseous $\mathrm{Br}_{2}, 60^{\circ} \mathrm{C}$ & 2 & 0 & 36 & 78 \\
$\mathrm{No} \mathrm{Br}_{2} \mathrm{Control}$ & 40 & 15 & 22 & - \\
\hline
\end{tabular}

Table 3. Bench-Scale Results for Best Sorbent, stored 90 days at varied conditions

\begin{tabular}{lccccc}
\hline & $\begin{array}{c}\text { Storage } \\
\text { Method }\end{array}$ & $\begin{array}{c}\text { Initial, } \\
\% \text { of } \\
\text { Bnlet }\end{array}$ & $\begin{array}{c}\text { Induction, } \\
\text { minutes }\end{array}$ & $\begin{array}{c}50 \% \\
\text { Breakthrough, } \\
\text { minutes }\end{array}$ & $\begin{array}{c}\text { Bromide } \\
\text { Concentration, } \\
\%\end{array}$ \\
\hline Gaseous $\mathrm{Br}_{2}, 25^{\circ} \mathrm{C}$ & $\mathrm{N}_{2}$ at $0{ }^{\circ} \mathrm{C}$ & 0 & 0 & 45 & 74 \\
Gaseous $\mathrm{Br}_{2}, 25^{\circ} \mathrm{C}$ & $\mathrm{N}_{2}$ at $25^{\circ} \mathrm{C}$ & 2 & 0 & 45 & 85 \\
Gaseous $\mathrm{Br}_{2}, 25^{\circ} \mathrm{C}$ & ${\text { Moist air at } 25^{\circ} \mathrm{C}}^{\circ}$ & 5 & 0 & 30 & 78 \\
Gaseous $\mathrm{Br}_{2}, 25^{\circ} \mathrm{C}$ & Dry air at $25^{\circ} \mathrm{C}$ & 3 & 0 & 45 & 75 \\
$\mathrm{No} \mathrm{Br}_{2}$ Control & $\mathrm{N}_{2}$ at $25^{\circ} \mathrm{C}$ & 40 & 15 & 22 & - \\
\hline
\end{tabular}

Table 3 shows the best-performing treated $\mathrm{AC}$ that was subjected to the different storage conditions (Column 2). Whether stored at $0{ }^{\circ} \mathrm{C}, 25^{\circ} \mathrm{C}$, under $\mathrm{N}_{2}$, and/or in dry air, each gave similar reactivities and capacities compared to the initial carbon. However, when stored in ambient air, results as indicated in Tables 1-3 show that the carbon had reduced reactivity and a fairly significant reduction in capacity, as shown by a much lower breakthrough time (Table 3 , Column 5). This is an important consideration, since most facilities are not designed to store treated ACs in tightly controlled environments. While speciation is of particular interest, this small sample set showed similarity between all the samples; therefore, no correlation between reactivity and bromine speciation is evident from these tests. 
Initial tests showed no change in the reactivity of a $5 \%$ gas-phase $\left(25^{\circ} \mathrm{C}\right)$ bromine-treated activated carbon (base carbon is Norit DARCO Hg) during storage under nitrogen. However, storage of the same carbon in ambient air showed a small decrease in reactivity and a significant decrease in capacity. There were slight changes in bromine speciation (defined as percent anionic bromide as determined by high-resolution $\mathrm{Br} 3 \mathrm{~d}$ XPS), but the changes did not appear to correlate with reactivities or capacities. Albeit this was a limited dataset, investigation of other bromine-treated carbons showed that little reactivity was lost, but capacities generally decreased with storage time.

Although initially limited in scope, the results were considered of sufficient merit to provide insight into what storage conditions may cause sorbent degradation. Preliminary results showed that under certain conditions (primarily storage in ambient air), notable performance degradation occurred, as measured by mercury capture efficiency. These preliminary results were of concern to many of the consortium members, who suggested that additional research be done with a matrix of variables to better understand possible aging effects and determine which factors in storage were of most concern.

Because the primary cost of AC injection technology is the ongoing cost of the carbon, reduced reactivity and capacity are of great concern. Therefore, determining if the mode of storage affects brominated carbons is important to the commercial long-term use of this technology.

\section{TESTING APPROACH - EFFECTS OF AGING ON TREATED ACTIVATED CARBONS}

To address project objectives, which Phase II project sponsors determined to be of the greatest importance, in a controlled experimental manner, the EERC used freshly created sorbent samples. The samples were all evaluated for reactivity and capacity using the EERC's mercury bench-scale system (also used in Phase I and II testing) under simulated flue gases; all samples were tested under the same conditions. This system has shown excellent repeatability in tests and has been used to evaluate the reactivity and mercury capacity for hundreds of sorbents in a fixedbed apparatus. Test results were compared to those obtained for DARCO Hg-LH, a commercially available halogenated carbon, which was also obtained from a fresh batch from Norit Americas.

To simulate realistic storage conditions, priorities were established and approved by project participants. The group decided the following variables would be useful: comparing various halogenation methods against a commercial "control" carbon; varying humidity content; varying heat in temperatures that would be normal under most storage regimes; and varying the length of time that the carbons would be aged under these conditions.

To ensure data quality, the EERC constructed storage chambers that allowed for accurate control of air temperature and relative humidity conditions. Ambient air was controlled to the stated conditions, which prior tests had indicated as most important (5). For the aging chambers, flowmeters ensured that water bubbling through impinger bottles flowed through dilution meters 
to the set relative humidity. Two separate portions of the chamber ensured that each temperature set point was maintained. Sorbents were stored in impinger bottles that allowed constant contact between the moderated air flow and the sorbent. Figure 1 shows the system that was constructed to allow full control of the carbons for this project.

Prior to starting tests, shakedown testing evaluated the controlled-environment chambers to ensure that flows were consistent and that the temperature and humidity of all chambers could be maintained within acceptable allowances.

To control for possible differences in the time required for development, production, and/or shipment of commercially treated AC, the EERC prepared fresh sorbents in the laboratory using gaseous elemental bromine treatment of DARCO Hg.

The composition of the simulated flue gas used for this project is shown in Table 4, which includes both low acid gas, typical of lignite-derived flue gas, and high acid gas conditions, typical of an eastern bituminous coal. In addition to bench-scale tests, analytical techniques were applied to further characterize and/or detect possible physical, surface, and chemical changes that may have occurred over increasing storage times under controlled conditions.

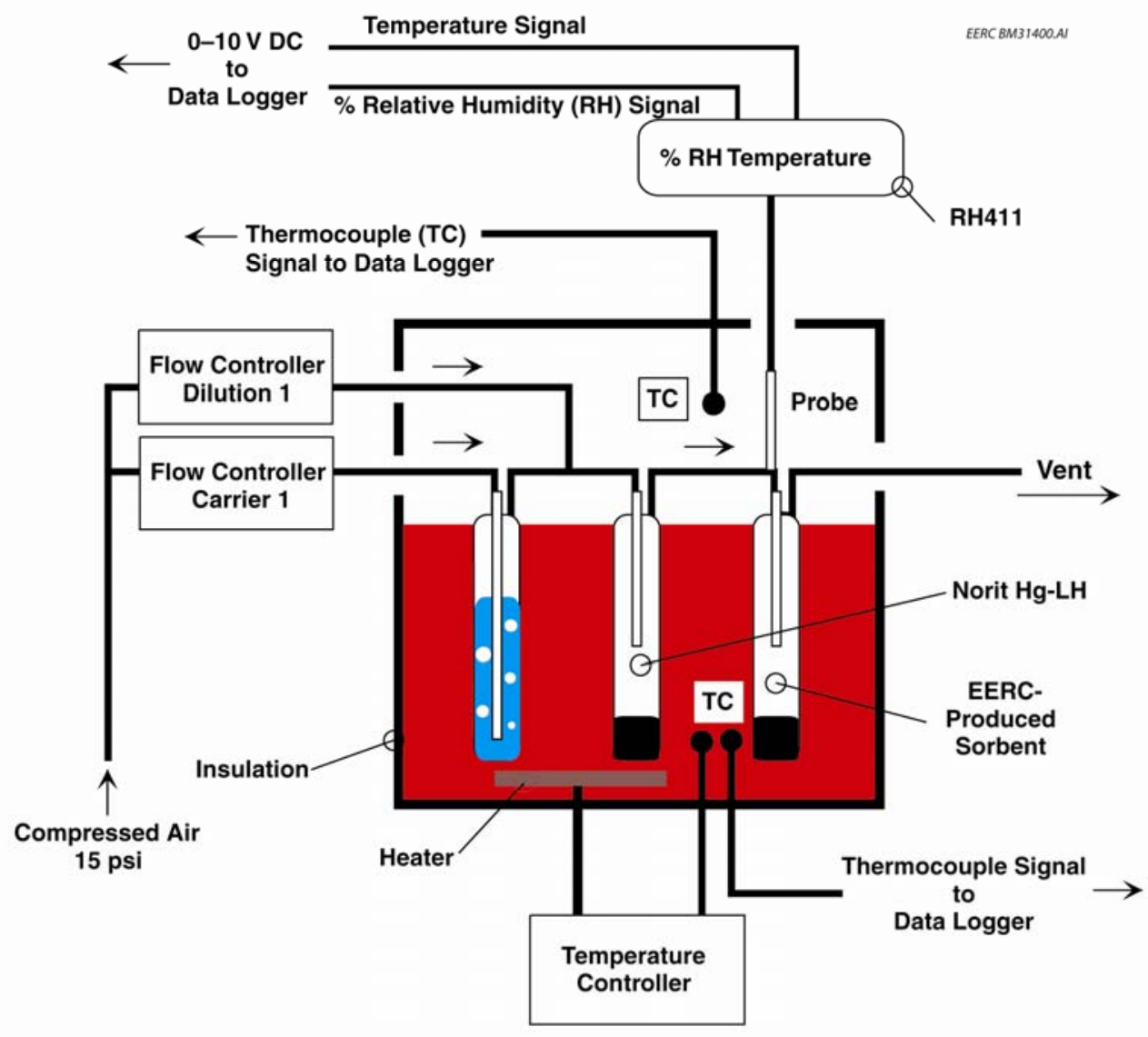

Figure 1. Aging chambers with temperature- and relative humidity-controlled environment. 
Table 4. Flue Gas Constituents for Test Conditions

\begin{tabular}{lcc}
\hline Flue Gas Constituent & Low Acid Gas Condition & High Acid Gas Condition \\
\hline $\mathrm{O}_{2}, \%$ & 6 & 6 \\
$\mathrm{CO}_{2}, \%$ & 12 & 12 \\
$\mathrm{H}_{2} \mathrm{O}, \%$ & 15 & 8 \\
$\mathrm{SO}_{2}$, ppm & 580 & 1600 \\
$\mathrm{~N}_{2}$ & Balance & Balance \\
$\mathrm{NO}$, ppm & 120 & 400 \\
$\mathrm{NO}_{2}, \mathrm{ppm}$ & 6 & 20 \\
$\mathrm{HCl}^{0}$ ppm & 1 & 50 \\
$\mathrm{Hg}^{0}$, ppm & 12 & 12 \\
\hline
\end{tabular}

\section{EERC Bench-Scale Mercury System and Test Procedure}

The EERC fixed-bed mercury system is used to determine the mercury reactivity and capacity of a given sorbent under different controlled flue gas conditions; it continues to be the best experimental approach for screening sorbents and has led to major discoveries concerning the effects of flue gas components on sorbent performance.

The thin-bed reactor consists of a Teflon ${ }^{\circledR}$-coated, 2.5-in.-diameter dust-loading filter holder. A quartz filter loaded with sorbent makes up the actual thin bed. The filters are uniformly coated with the sorbents by pulling a vacuum on the outlet side of the filter holder and feeding the sorbent at the inlet side. Because sorbents can often last several hours before mercury breaks through a fixed bed, even one of such thin depth as these, a technique was established at the EERC to dilute the sorbent with an inert substance that does not affect pressure drop and to conduct all tests using this method. This reduces the $50 \%$ breakthrough time to less than 2 hours, while still providing consistent, reliable comparative results between carbons.

The EERC's procedure for screening $\mathrm{Hg}$ sorbents in a fixed-bed bench-scale system follows these steps. Before the start of each test, the inlet mercury concentration in the flue gas is measured by the continuous mercury monitor (CMM). The sample is then plumbed into the system while ambient air is analyzed for mercury until the amount of mercury measured is less than $0.3 \mu \mathrm{g} / \mathrm{m}^{3}$. At the start of the test, flue gas is applied to the fixed bed at $29.9 \mathrm{scfm}$. For each sample, a measurement is made of the initial reactivity or induction period. Flue gas is then passed through the sample until mercury breakthrough reaches at least $75 \%$ of the inlet concentration. A diagram of the system is shown in Figure 2.

For the EERC bench-scale mercury test system, a CMM was used that is based on atomic absorption. A PS Analytical CMM with a wet-chemistry conditioning/conversion unit was used upstream of the filter sorbent assembly to measure both the elemental and total mercury at the inlet and outlet of the fixed-bed reactor. In order to monitor oxidized forms of mercury, a $\mathrm{SnCl}_{2}$ reduction cell is used prior to the analyzer to convert all forms of mercury to $\mathrm{Hg}^{0}$ for analysis. 


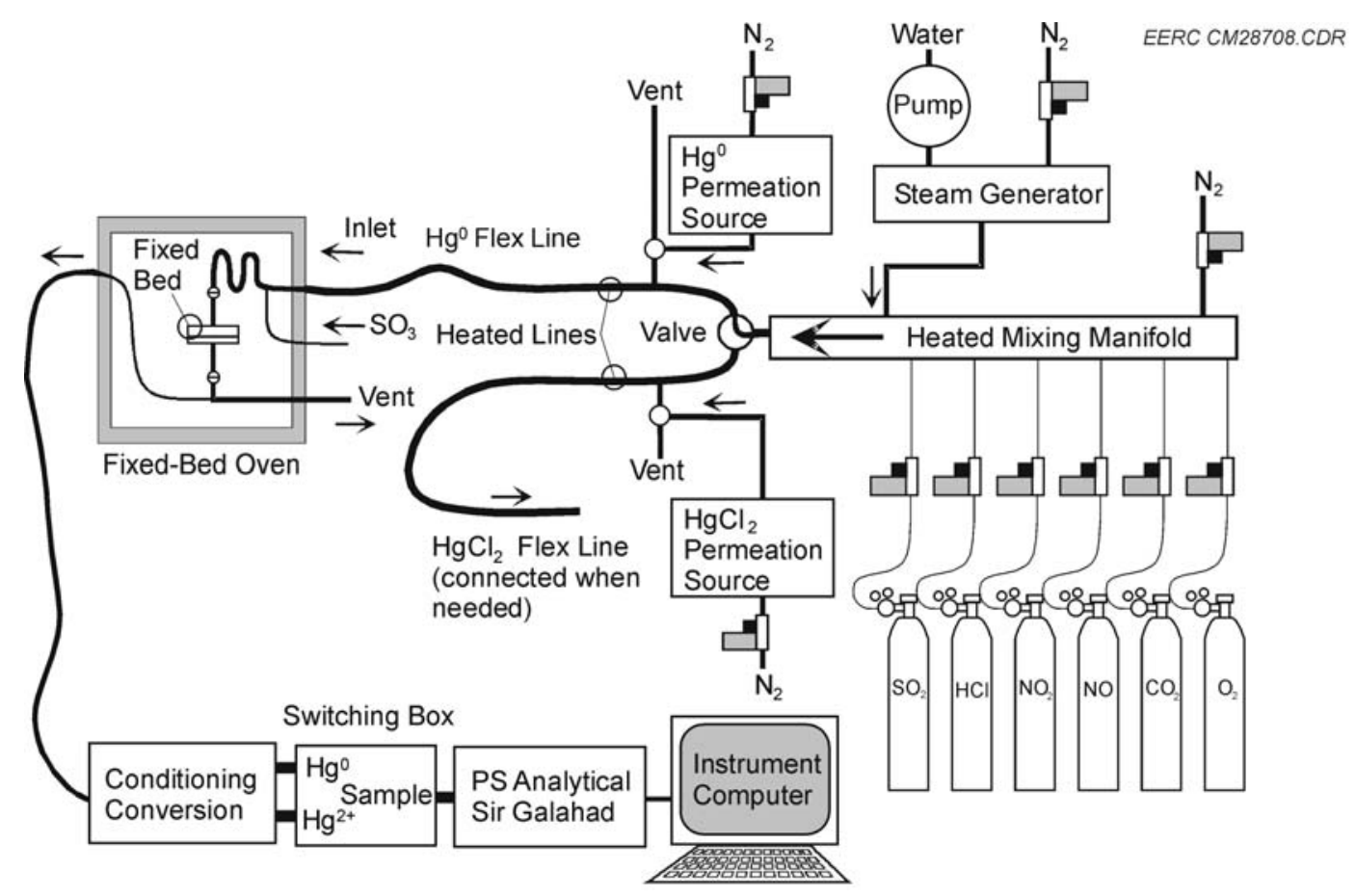

Figure 2. Schematic of EERC bench-scale apparatus.

Outside labs were used to conduct the XPS and x-ray absorption fine structure (XAFS). analysis, which require very specialized equipment and special expertise for the analysis.

\section{XPS Experimental}

XPS data for brominated carbons were obtained by Evans Analytical Group stored under the temperature and humidity conditions specified in the Test Results and Analyses section. Surface composition data was obtained for $\mathrm{C}, \mathrm{O}, \mathrm{Br}$, and several other inorganic species. Highresolution spectra were obtained for $\mathrm{C}, \mathrm{O}, \mathrm{Cl}, \mathrm{S}, \mathrm{Al}, \mathrm{Si}, \mathrm{Fe}$, and $\mathrm{Br}$ to determine the chemical state.

The XPS data were acquired using a probe beam of focused, monochromatic $\mathrm{Al} \mathrm{K}_{\alpha}$ radiation. The X-rays generate photoelectrons that are energy-analyzed and counted to reveal the atomic composition and chemistry of the sample surface. The escape depth of the photoelectrons limits the depth of analysis to the outer $\sim 50 \AA$. The data presented include low-resolution survey scans, which give the full spectrum between 0 and $1400 \mathrm{eV}$ binding energy. Also included in the data are high-resolution spectra from selected elements, which give chemical state information. The spectra are used to obtain surface composition by integrating the areas under the photoelectron peaks and applying empirical sensitivity factors.

\section{Analytical Conditions}

Instrument:

Physical Electronics 5802 Multitechnique 
X-Ray Source:

Analysis Area:

Take-Off Angle:

Charge Correction:

Charge Neutralization:
Monochromatic Al K $1486.6 \mathrm{eV}$

$1.5 \mathrm{~mm} \times 0.6 \mathrm{~mm}$

$45^{\circ}$

C-C, C-H in C 1s spectra set to $284.8 \mathrm{eV}$

Low energy electron and ion floods

\section{XAFS Experimental}

Detailed XAFS speciation data (for the different forms of bromine) on the carbon surfaces were evaluated by Dr. Frank Huggins from the University of Kentucky using Brookhaven National Laboratory facilities in Brookhaven, New York. The XAFS measurements were made at the bromine K-absorption at the National Synchrotron Light Source (NSLS), Brookhaven National Laboratory, New York, during the period March 13-16, 2009. XAFS measurements were made in both absorption and fluorescence geometry at beam-line X18-B at NSLS using a PIPS fluorescence detector to detect the x-rays emitted by bromine in response to the x-ray absorption process. The char samples were held in the x-ray beam as powders in ultrathin polypropylene baggies. The Br XAFS spectra were collected as a function of energy from about $200 \mathrm{eV}$ below the $\mathrm{Br} \mathrm{K}$ absorption edge at $13,474 \mathrm{eV}$ to as much as $1000 \mathrm{eV}$ above the edge by measuring the absorption and fluorescence as a function of the angular rotation of a silicon (111) monochromator. The absorption spectrum of a SOMAR pellet of $\mathrm{KBr}$, obtained simultaneously in absorption geometry, was used as the primary energy calibration standard for bromine. The major peak in the derivative XAFS spectrum of $\mathrm{KBr}$ was assumed to occur at 13,474 eV.

In addition, the EERC performed surface analysis using carbon tetrachloride $\left(\mathrm{CCl}_{4}\right)$ analysis to determine relative change in the surface area of the sorbents as they aged under various conditions.

\section{Quality Measures}

For this project, production of the ACs, storage/aging tests, and bench-scale measurement were conducted in controlled laboratory environments that operate according to University of North Dakota, state, and federal environmental guidelines. As was done in the original exploratory task to test aging effects on treated carbons, several controls were implemented to ensure valid and reliable data. First, all treated carbon(s) were produced at the same time to ensure that production variables were not the cause of different capacities/reactivities and to ensure that researchers were beginning with fresh carbons.

Also, using a simulated flue gas of known concentrations of various constituents allowed maximum control and minimal variability in flue gas concentrations. All gases were of trace metal grade and had flowmeters to ensure accurate flow measurements.

All sorbent samples were placed in storage chambers that were maintained at the stated test conditions over several months. Procedures were implemented to ensure steady-state conditions were maintained for all aging chambers. All chambers were monitored carefully, and humidity and temperatures were logged and held constant. 
For the EERC bench-scale system, the process was repeatable for mass loadings down to $10 \mathrm{mg}$. The thin-bed assembly was maintained at the desired temperature inside an oven that could be controlled to $\pm 1^{\circ} \mathrm{C}$. Previous tests established the repeatability of the results and demonstrated good mercury mass balances. The CMM that is part of this system is regularly calibrated using standard injections of mercury vapor at known temperature and volume. The known inlet mercury concentration produced by the bench-scale system was measured before and after each test to ensure there were no problems with the equipment during the test. The known inlet mercury concentration was based on the total flow rate of the flue gas constituents and the permeation rates of the elemental mercury and mercuric chloride sources. The flow rates are controlled by mass flow controllers that were periodically calibrated with a Gilibrator, which is a primary standard for flow measurement. The permeation rates of the mercury sources were periodically confirmed with either U.S. Environmental Protection Agency Method 101A samples or Ontario Hydro method samples.

For analysis of the treated ACs, routine and advanced analytical techniques were applied to provide further insight into possible changes in a sorbent's physical, surface, and chemical properties. Applicable quality assurance measures were applied for each method, which includes calibration of the equipment with known standards.

\section{TEST RESULTS AND ANALYSES}

Based on the revised schedule, as well as discussions with sponsors, a revised test matrix was developed and sent to sponsors for approval; the two major changes were inclusion of DARCO Hg-LH as a control against which the carbons could be compared versus a larger variety of bromination concentrations for the carbon. DARCO Hg-LH was provided by Norit Americas as part of a fresh lot and was stored under inert gases in a freezer until testing began. The other change to the matrix included two tests with carbons that were subjected to very high temperatures to see if surface changes occurred at these elevated temperatures.

Because the funds for this project were very limited, a small parallel project was conducted through the Center for Air Toxic Metals ${ }^{\circledR}\left(\mathrm{CATM}^{\circledR}\right)$ to expand the carbons and test variables. Between the two parallel projects, which are both reported here, the following aging regimes were established, although for some samples, very limited testing was conducted:

- DARCO Hg-LH stored at $80 \%$ humidity and $120^{\circ} \mathrm{F}$ (control sample at this temperature), plus a duplicate to use for comparative purposes if test results were questionable

- $5 \%$ brominated standard DARCO, stored at $80 \%$ humidity and $120^{\circ} \mathrm{F}$

- $15 \%$ brominated standard DARCO, stored at $80 \%$ humidity and $120^{\circ} \mathrm{F}$

- DARCO Hg-LH stored at $80 \%$ humidity and $80^{\circ} \mathrm{F}$ (control sample at this temperature)

- $5 \%$ brominated standard DARCO, stored at $80 \%$ humidity and $80^{\circ} \mathrm{F}$ 
- $5 \%$ brominated standard DARCO, stored at $20 \%$ humidity and $80^{\circ} \mathrm{F}$

- DARCO Hg-LH stored at $20 \%$ humidity and $80^{\circ} \mathrm{F}$

Special emphasis was made on comparing the results from baseline (Day 0) tests for all samples and the final results for the fully aged samples. To take the most advantage of limited funds, most analysis was conducted for the samples that were stored at $80 \%$ relative humidity, which is considered to be the average humidity found in most storage facilities, and $80^{\circ} \mathrm{F}$, which is again about the average room temperature. XPS and XAFS were conducted on samples from Day 0 (baseline), Day 90, and the conclusion of the testing (initially planned for 180 days, but actually worked out to be 275 days because of contamination issues with the bench-scale system that again required a complex, lengthy diagnostic period before allowing the carbons to be removed from their aging chambers).

To also evaluate the extremes of temperatures, the baseline (Day 0) $5 \%$ brominated DARCO and the DARCO Hg-LH were also subjected to temperatures of $700^{\circ} \mathrm{F}$ for 2 minutes, cooled, and then tested on the bench-scale system.

To ensure proper quality control, the bench-scale system was routinely checked against a sample of DARCO Hg; this AC has been stored under inert gas in a freezer for a number of years. It has consistently shown the same results on the bench scale during this time period and provides the ultimate control for this project. As the project was beginning, the routine system shakedown included testing the bench-scale system to ensure that mercury induction and breakthrough curves fit baseline curves that have been obtained over hundreds of tests of the stored DARCO Hg. Unfortunately, the initial tests failed, causing an idling of this project to troubleshoot the entire system for possible mercury contamination. Each component was checked. Because the changes measured in the ACs during this project needed to be very precise, it was crucial to ensure that proper quality assurance/quality control could be maintained. This resulted in an initial delay of several weeks while the system had several components and tubing replaced to ensure that no contamination was present. After significant evaluation, the chemistry on the elemental side of the conversion unit for the dedicated mercury emission monitor was determined to be at issue. The chemistry on this side of the analyzer was changed from a $\mathrm{NaOH}-$ $\mathrm{KCl}$ solution to one using tris buffer, which has proven successful. This is outside of the scope of this project and is a topic for a possible paper later.

All carbons, including the fresh DARCO Hg and the EERC-produced brominated carbon, were stored in sealed containers under an inert gas at freezing temperatures prior to beginning the testing to guard against chemical and physical changes.

Carbons were evaluated for mercury sorption properties using the following protocol. Carbons were diluted with a -400 mesh diatomaceous earth (DE) sample (Celite) in a ratio of one part of $\mathrm{AC}$ to two parts of $\mathrm{DE}$ to allow for uniform distribution on the filter surface when a vacuum was drawn through it. This was found to be the optimal level of dilution that allowed reactivity of the carbons to be discriminated. Several batches were tested to obtain a mean $50 \%$ breakthrough time of $0.68 \mathrm{hr}$. 
Several runs of the frozen samples were compared in the early part of this project, with tighter resolution of the test intervals in the beginning of the tests than toward the end. The results showed good reproducibility, providing a quality assurance/quality control check for this storing protocol and assurance that no carbon reactivity degradation was noted as a result of freezing and thawing.

Initial testing to develop proper protocols included grinding and sieving the carbons. However, this introduced variability, possibly as a result of changes to the carbon surfaces and/or the chemical composition resulting from this processing. Consequently, the carbons were run on an as-received basis with the sieved DE after results were demonstrated as reproducible.

When testing could finally resume, the chambers were filled with sufficient carbons to allow for the full suite of tests to be conducted, as well as for splits to be taken at each time interval. At each test interval, splits of each carbon were taken, put into a vial, filled with inert gas, and immediately returned to the freezing storage. The control chambers were brought to a constant temperature and relative humidity $(\mathrm{RH})$ and monitored prior to introduction of each of the carbons. A baseline split was taken of each sample.

\section{Bench-Scale Evaluations of Carbon Reactivity and Capacity}

Because of the tight controls needed to ensure reliable and valid results, the delays resulted in testing beginning at the same time as several other competing projects. The resolution of this project had to be modified very slightly in order to accommodate a fixed-testing schedule. Therefore, testing was done at 0 day, 5-6 days, 20 days, 40 days, 132 days, and 275 days in the experiments. After completion of the 275 days of testing, samples of the $5 \%$ brominated sample that had been stored at $<0^{\circ} \mathrm{C}$ were placed in the aging chambers for an additional short-term test for 2 and 6 days. The results of the bench-scale reactivity tests are reported in Table 5 and are discussed separately below for each of the carbon types.

\section{Control Sample}

A sample of Norit LH was stored in a freezer for the length of the tests. A portion was removed at each time interval and tested on the bench scale to ensure that the tests would be reproducible with time; that is, no changes had occurred in the experimental bench-scale equipment such as contamination, gas flow changes, degradation of the analyzer gold trap, or analyzer chemistry. The Day 0 tests for as-received Norit LH from the freezer showed a 50\% breakthrough time of $0.62 \mathrm{hr}$ in two separate runs (Table 5). 100\% capture occurred at the start of the test. Repetition of the test at each time interval gave exactly the same $50 \%$ breakthrough time and initial capture reactivity. Thus reproducibility of the test equipment and protocol was ensured.

\section{Norit LH}

The Day 0 tests with as-received Norit LH from the freezer showed a 50\% breakthrough time of $0.62 \mathrm{hr}$ in two separate experiments as described above (Table 5). As a measure of initial reactivity, $100 \%$ capture occurred at the start of the test. 
Table 5. 50\% Breakthrough Times (hr) for Brominated Samples under Low Acid Gas Conditions

\begin{tabular}{lcccccccr}
\hline Day & LH & & LH & & $5 \%$ & & $15 \%$ \\
& Frozen & $80 / 80$ & $120 / 80$ & $80 / 20$ & $80 / 80$ & $120 / 80$ & $80 / 20$ & $120 / 80$ \\
\hline 0 & 0.62 & & $0.62,0.62$ & & & 0.56 & \\
2 & & & & & $0.59^{*}$ & $0.59^{*}$ & & \\
5 & & & & & 0.49 & & & \\
6 & 0.62 & 0.62 & & & $0.49^{*}$ & $0.50^{*}$ & & 0.45 \\
20 & 0.62 & & 0.55 & & 0.45 & 0.44 & & \\
40 & 0.62 & 0.53 & & & 0.43 & & & 0.47 \\
132 & 0.62 & 0.62 & 0.62 & & & 0.57 & 0.61 & 0.50 \\
275 & 0.62 & 0.54 & 0.60 & 0.70 & 0.46 & 0.42 & 0.46 \\
\hline
\end{tabular}

* Repeated short-term aging tests.

Under the $80^{\circ} \mathrm{F} / 80 \% \mathrm{RH}$ conditions, storage for 6 days produced no change (Table 5) in either the $50 \%$ breakthrough time or initial reactivity. However, storage of the LH sample for 40 days showed a decrease in the $50 \%$ breakthrough time $(0.53 \mathrm{hr})$, but the initial reactivity was still $100 \%$ capture. Further storage under these conditions for 132 days gave a return to $0.62 \mathrm{hr}$ and for 275 days gave again a lower value $(0.54 \mathrm{hr})$. There is no definitive explanation for this oscillation, but it is likely that the two low values resulted from an unevenness in the very thin bed thickness that went unnoticed. This variation in the control test breakthrough time for frozen Norit LH was not observed. So it is possible that the sorbent particles became stickier as a result of storage under humid conditions and this caused the bed to become slightly less uniform.

For the $120^{\circ} \mathrm{F} / 80 \% \mathrm{RH}$ conditions, the 20 -day storage sample showed a lower value for the $50 \%$ breakthrough time $(0.55 \mathrm{hr})$. However, the subsequent longer-term tests showed no decrease in $50 \%$ breakthrough. Again, the lower value for one test at the $80 \% \mathrm{RH}$ storage condition could be explained by a bed unevenness.

The $80 / 20$ conditions showed an increase in $50 \%$ breakthrough time to 0.70 min for the 275-day period, indicating an increase in capacity over the longer period. Increases in capacity cannot be attributed to bed uneveness as decreases can, but the longer $50 \%$ breakthrough time is difficult to explain as something other than a change in sample. Unfortunately, there was only one test with LH aging under the dry conditions. Changes in the sample chemistry that may be responsible are discussed in the XPS section.

\section{5\% Brominated FGD (EERC sample)}

At Day 0 , the $5 \%$ brominated sample showed $50 \%$ breakthrough at $0.56 \mathrm{hr}$, which was less than that of the Norit LH sample. Initial reactivity was high (100\% capture).

For the $80^{\circ} \mathrm{F} / 80 \% \mathrm{RH}$ storage conditions, the 5-day sample showed significant loss of capacity. The $50 \%$ breakthrough curve shortened from 0.56 to $0.46 \mathrm{hr}$. At the 20 -day point, a similar breakthrough time was observed, and the 40-day sample showed a small decrease to $0.43 \mathrm{hr}$; the test at 275 days gave $0.46 \mathrm{hr}$. 
Thus the change in $50 \%$ breakthrough actually occurred in the first 5 days. No change was observed in the initial reactivity.

No 5- to 6-day sampling was done with the $120^{\circ} \mathrm{F} / 80 \% \mathrm{RH}$ conditions. But after 20 days' storage, the $50 \%$ breakthrough had dropped to $0.44 \mathrm{hr}$, comparable to that of the $80^{\circ} \mathrm{F} / 80 \% \mathrm{RH}$ sample at 20 days. Subsequent testing at 152 and 290 days showed an increased capacity at 152 days and a decrease to 0.43 at 290 days.

New $5 \%$ brominated samples were started in the temperature/humidity chambers following completion of the 275 -day tests. The $80^{\circ} \mathrm{F} / 80 \% \mathrm{RH}$ and the $120^{\circ} \mathrm{F} / 80 \% \mathrm{RH}$ samples both had $50 \%$ breakthrough times of $0.59 \mathrm{hr}$ after 2 days' storage and 0.49 and $0.50 \mathrm{hr}$, respectively, after 6 days' storage. These experiments verified that the decrease in capacity occurred rapidly, although the times differed from those obtained earlier.

The $5 \%$ brominated sample stored at $80^{\circ} \mathrm{F} / 20 \%$ RH showed a small increase in the $50 \%$ breakthrough time to $0.61 \mathrm{hr}$. This increased capacity is consistent with the increase observed for the LH carbon over 275 days.

\section{5\% Brominated FGD (EERC sample)}

The $15 \%$ brominated sample exhibited a much shorter $50 \%$ breakthrough time at Day 0 compared to the $\mathrm{LH}$ and $5 \%$ brominated sample. The initial reactivity was $100 \%$ capture.

Interestingly, the 6-day sample showed a slightly longer $50 \%$ breakthrough than the Day 0 sample, in contrast to the $\mathrm{LH}$ and $5 \%$ brominated sorbents described above. Further storage showed further improvement in capacity, so that at 275 days, its capacity exceeded two of the aged $5 \%$ brominated samples.

\section{Summary of Mercury Sorption Data}

All the stored samples gave $100 \%$ capture at the start of the experiments. Thus no loss of initial capture reactivity could be observed. When the initial capture is $100 \%$, the experimental method is inadequate for determining any very small change in initial reactivity.

Plots of the $50 \%$ breakthrough time versus the aging time for the various carbons and conditions are shown in Figure 3. In Figure 4, the $\mathrm{x}$ intercept is set to the initial value (Day 0 value) for each carbon. The slopes can be positive or negative as indicated in the discussion above. The $\mathrm{R}^{2}$ values are small for most of the trendlines. In the case of the $5 \%$ brominated carbon, the larger losses over the initial intervals are not adequately represented by the trendlines.

The following generalizations can be made:

- The LH carbon stored at $32^{\circ} \mathrm{F}$, did not change capacity. 


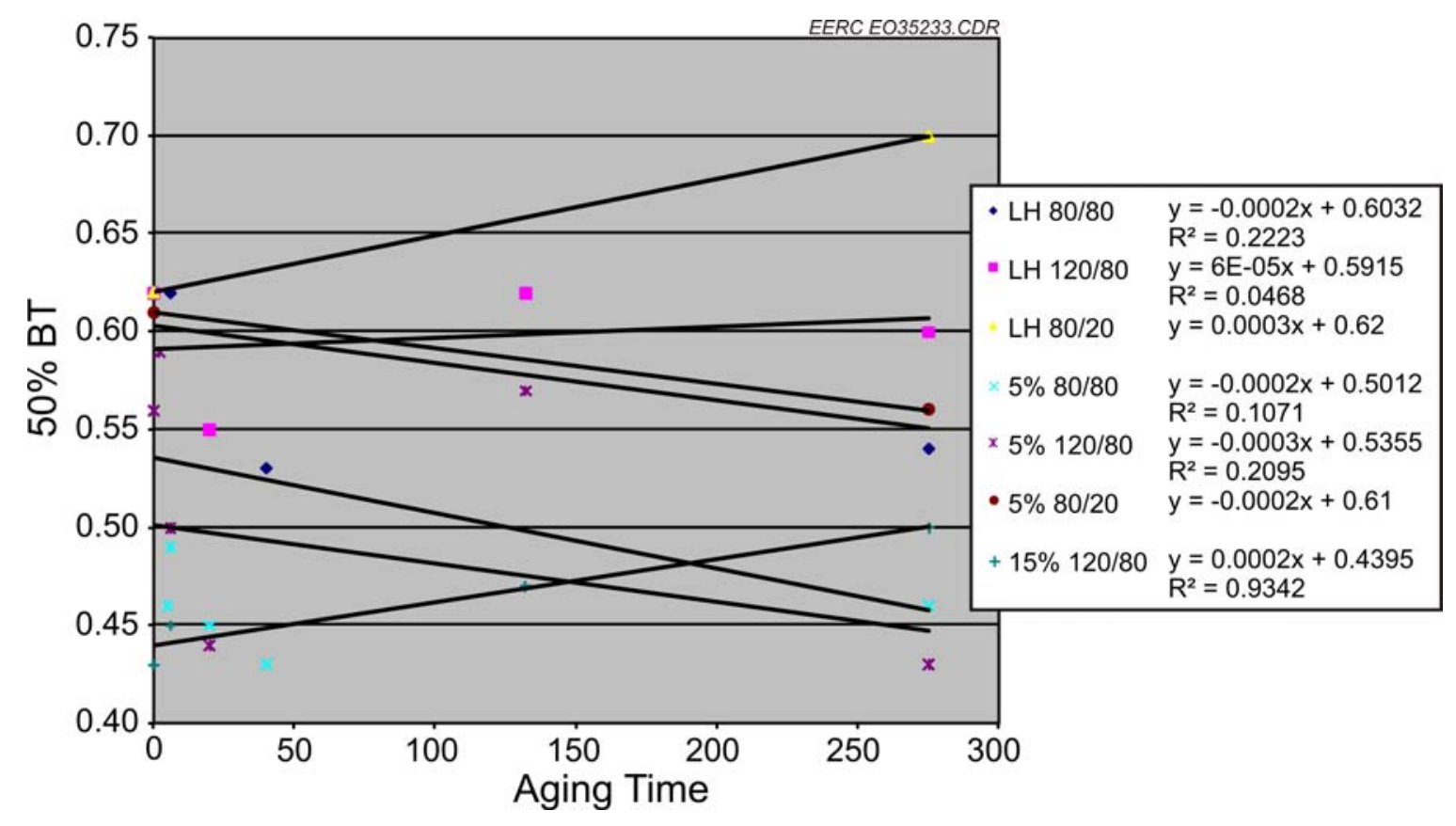

Figure $3.50 \%$ breakthrough vs. aging time.

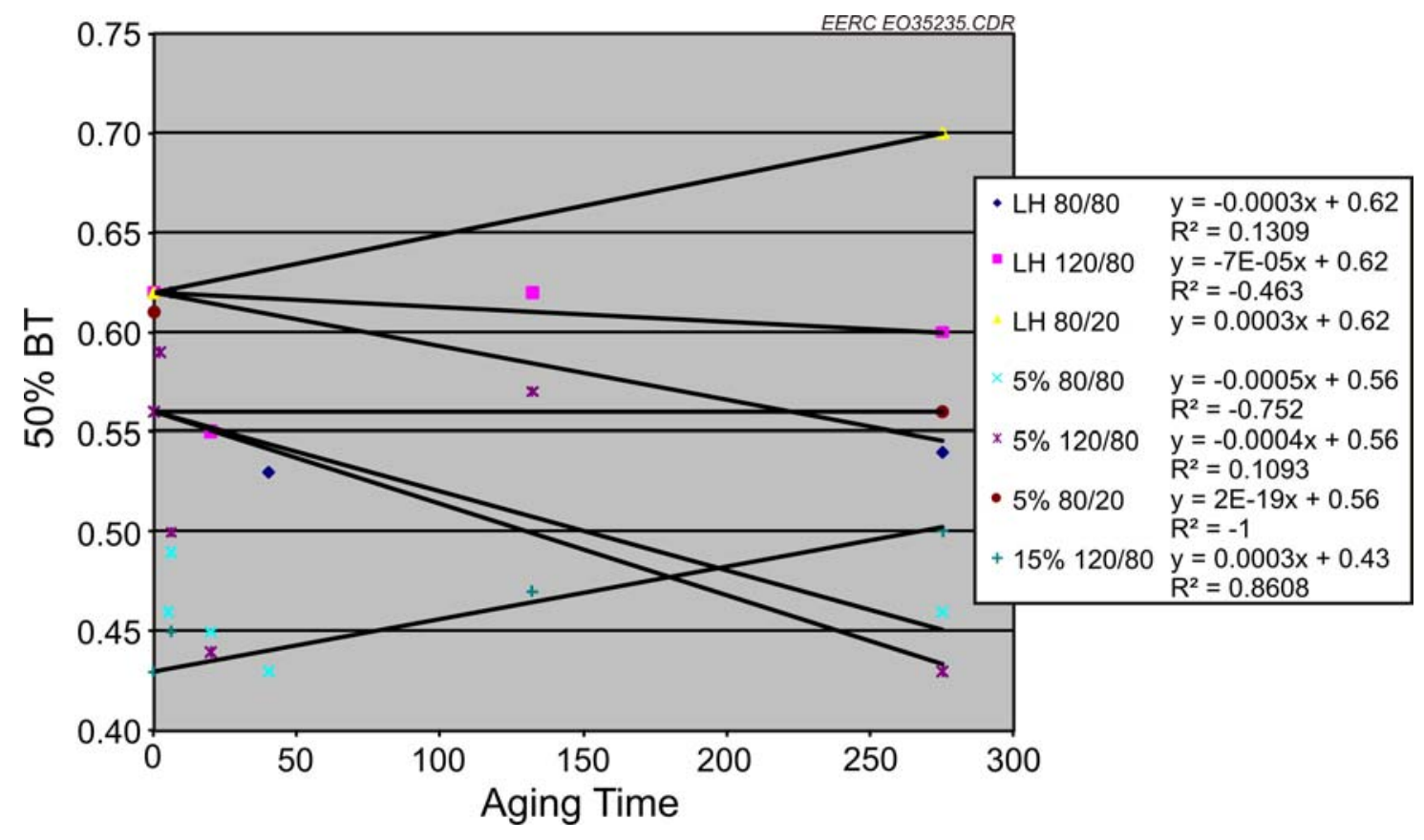

Figure $4.50 \%$ breakthrough vs. aging time (intercept set to Day 0 value). 
- It is unlikely that the LH carbon changed capacity or reactivity under storage at $80 \%$ humidity. It is likely that the LH carbon increased capacity when stored at $20 \%$ humidity $\left(80^{\circ} \mathrm{F}\right)$.

- The EERC 5\% brominated carbon lost some capacity in the first week when stored under $80 \%$ humidity, then little change occurred.

- It is likely the $5 \%$ brominated sample stored at $20 \%$ humidity showed no net loss of capacity over the 275 days.

- The EERC $15 \%$ brominated sample showed an increased capacity consistently over the entire storage period of 275 days.

\section{Sample Analysis Using XPS}

Surface analysis information provided by XPS data was obtained by analysis by Evans Analytical Group. Surface concentration data were obtained from the low-resolution scans for carbon, oxygen, bromine, and several inorganic species. High-resolution spectra were obtained for carbon (C 1s), oxygen (O 1s), chlorine $(\mathrm{Cl} 2 \mathrm{p})$, silicon (Si 2p), sulfur ( $2 \mathrm{p})$, sodium (Na 2s), and bromine (addressed later) to determine their chemical state.

\section{Br Surface Concentrations}

Of major interest were the bromine surface concentrations (see Table 6). The Norit LH had the lowest bromine concentration, followed by the 5\% brominated Norit FGD, then the $15 \%$ brominated sample. Trendlines for the change of surface bromine concentration with aging (Figure 5) show small negative slope for LH stored under all three conditions. The 5\% brominated carbon also showed a negative slope for storage under high humidity conditions, but a positive slope for the storage under dry conditions. The $15 \%$ brominated carbon showed a large increase in surface bromine after storage for 275 days.

It is important to understand that the bulk samples did not change $\mathrm{Br}$ concentration, only the surfaces, perhaps by migration to (LH and 5\%) or from (15\%) the interior of the sample. The 2.4 atom $\% \mathrm{Br}$ corresponds roughly to $15 \% \mathrm{wt} \%$, so it unlikely that $\mathrm{Br}$ was lost from the sample to the gas phase. Nevertheless, the $\mathrm{Br}$ concentration on the surface may be important to reactivity to mercury.

Other differences were associated with the mineral content of the LH and the DARCO FGD. The LH had higher $\mathrm{Na}, \mathrm{Mg}$, and $\mathrm{Ca}$ and lower $\mathrm{Al}$ and $\mathrm{Si}$ (clay). There was little change in these concentrations during storage. 
Table 6. XPS Surface Concentrations (atomic \%)*

\begin{tabular}{lccccccccccc}
\hline Sample & $\mathrm{C}$ & $\mathrm{O}$ & $\mathrm{Na}$ & $\mathrm{Mg}$ & $\mathrm{Al}$ & $\mathrm{Si}$ & $\mathrm{S}$ & $\mathrm{Cl}$ & $\mathrm{Ca}$ & $\mathrm{Fe}$ & $\mathrm{Br}$ \\
\hline Norit Hg-LH & 80.0 & 12.5 & 1.8 & 0.8 & 0.5 & 0.9 & 0.5 & 0.3 & 1.7 & 0.1 & 1.0 \\
Heated Norit LH & 82.7 & 8.7 & 2.2 & 0.5 & 0.6 & 0.9 & 0.5 & 0.5 & 1.7 & 0.1 & 1.7 \\
C5BO 5\% Br & 83.3 & 10.6 & - & 0.6 & 0.9 & 1.3 & 0.6 & 0.2 & 1.1 & 0.2 & 1.2 \\
Heated C5BO 5\% Br & 83.3 & 10.9 & - & 0.4 & 0.6 & 1.2 & 0.6 & 0.2 & 1.4 & 0.2 & 1.2 \\
C5BR 15\% Br & 86.0 & 8.6 & - & 0.3 & 0.5 & 0.9 & 0.7 & 0.2 & 1.2 & 0.1 & 1.7 \\
5\% 80/80 5 days & 84.3 & 10.7 & 0.1 & 0.6 & 0.5 & 1.1 & 0.4 & $<0.1$ & 1.2 & - & 1.1 \\
5\% 80/80 40 days & 83.0 & 11.8 & - & 0.5 & 0.4 & 1.4 & 0.5 & $<0.1$ & 1.4 & - & 0.9 \\
LH 80/80 40 days & 78.9 & 14.3 & 1.6 & 0.9 & 0.4 & 0.9 & 0.4 & $<0.1$ & 1.8 & - & 0.8 \\
LH 80/20 275 & 80.4 & 13.2 & 1.4 & 0.9 & 0.4 & 0.8 & 0.5 & - & 1.5 & 0.2 & 0.8 \\
LH 80/80 275 & 78.6 & 14.6 & 1.6 & 0.9 & 0.5 & 0.8 & 0.5 & - & 1.7 & 0.1 & 0.8 \\
LH 120/80 275 & 78.8 & 14.3 & 1.5 & 0.9 & 0.5 & 1.1 & 0.5 & - & 1.6 & - & 0.9 \\
5\% 80/20 275 & 83.4 & 11.4 & - & 0.4 & 0.8 & 1.2 & 0.6 & - & 1.2 & - & 1.0 \\
5\% 80/80 275 & 83.8 & 11.4 & - & 0.5 & 0.8 & 1.1 & 0.4 & - & 1.1 & 0.2 & 0.8 \\
5\% 120/80 275 & 80.9 & 13.4 & - & 0.6 & 1.2 & 1.4 & 0.2 & - & 1.3 & 0.3 & 0.8 \\
15\% 120/80 275 & 81.2 & 11.4 & 0.2 & 0.5 & 0.9 & 1.4 & 0.5 & - & 1.3 & 0.2 & 2.4 \\
Darco HgLH T80 & 79.1 & 14.2 & 1.5 & 0.9 & 0.7 & 0.8 & 0.4 & - & 1.7 & - & 0.8 \\
$\quad$ RH80 Day 132 & & & & & & & & & & & 0.9 \\
Darco HgLH T120 & 79.2 & 13.9 & 1.6 & 0.9 & 0.6 & 1.0 & 0.5 & - & 1.5 & - & 0.9 \\
$\quad$ RH80 Day 132 & & & & & & & & & & & 0.9 \\
FGD 5\% Br 2 T80 & 83.9 & 11.2 & - & 0.5 & 0.7 & 1.1 & 0.4 & - & 1.0 & 0.2 & 0.9 \\
$\quad$ RH80 Day 132 & & & & & & & & & & & 0.1 \\
FGD 5\% Br 2 T120 & 83.0 & 12.4 & - & 0.6 & 0.9 & 1.0 & 0.2 & - & 1.1 & 0.2 & 0.6 \\
$\quad$ RH80 Day 132 & & & & & & & & & & & \\
FGD 5\% HBr - Load & 76.2 & 15.6 & - & 1.8 & 1.3 & 1.3 & 0.6 & - & 1.7 & 0.3 & 1.3 \\
\hline
\end{tabular}

* Normalized to $100 \%$ of the elements detected. XPS does not detect $\mathrm{H}$ or $\mathrm{He}$.

Detection limits are typically between $0.05 \%$ and $1.0 \%$ for other elements.

A dash "-" indicates the element was not detected.

\section{Correlation of Bromine Concentration Data with Carbon Capacity}

It was noted above that the capacity of the $15 \%$ brominated sample and the LH carbon stored at dry conditions (80/20) increased with aging time, whereas little change or decrease was found for the other storage cases. The increase in surface bromine could perhaps explain the increase in the $50 \%$ breakthrough time observed for the $15 \%$ brominated sample during storage. A plot of $50 \%$ breakthrough time versus \% surface bromine for all the carbons and conditions is shown in Figure 6. These plots reveal that positive slopes are obtained for all the conditions except the LH at 80/20, although the $\mathrm{R}^{2} \mathrm{~s}$ for all the curves are low. Thus we could conclude that for the $15 \%$ brominated carbon, the large increase in surface bromine may be sufficient to increase the capacity, whereas for other carbons and conditions, other factor(s) must also play an important role in reducing the capacity. Indeed, other surface chemistries change considerably during aging that would deplete the capacity. 


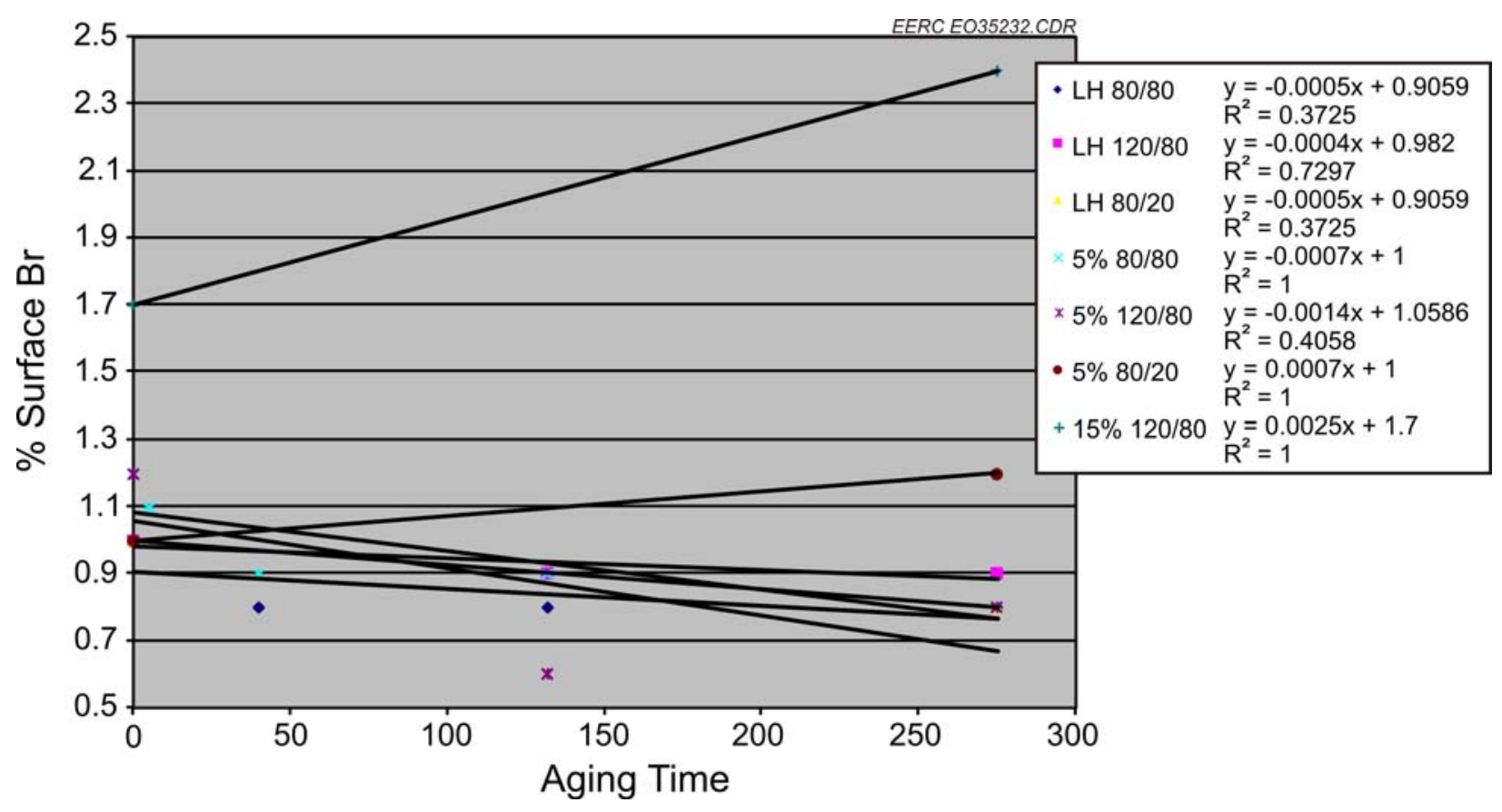

Figure 5. Percentage of surface Br vs. aging time.

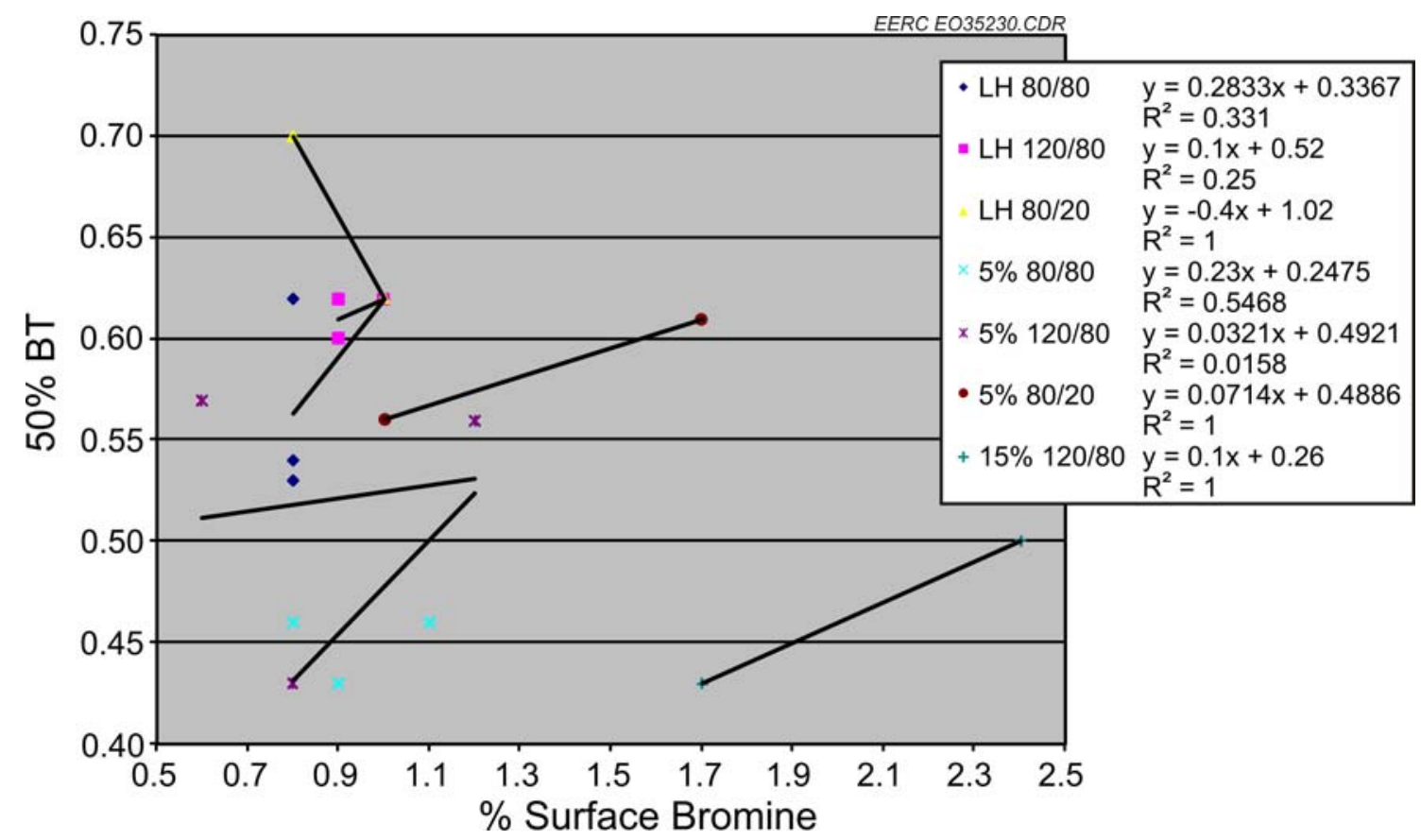

Figure $6.50 \%$ breakthrough vs. percentage of surface Br. 


\section{Element Speciation}

Carbon speciation of the initial samples indicated that the Norit LH had more carboxylate and carbonate groups than the EERC 5\% and 15\% brominated carbons (Table 7). The higher concentration of carboxylate and carbonate is indicative of more oxidation having occurred during its preparation, most likely the bromination procedure. Amounts of phenolic and carbonyl carbons are roughly similar.

Storage of all carbons gave increased amounts of carboxylate. The trendlines for the change in carboxylate with aging are shown in Figure 7 . The slopes for all of the storage conditions are positive, indicating oxidation during the storage, as expected. The slopes are similar except for the lower slope of the LH stored at $20 \%$ humidity. Similar increases are seen for the accumulation of phenolic, carbonyl, and carbonate carbon over 275 days.

Table 7. Carbon Surface Chemistries (\% of total C)

\begin{tabular}{lcccccc}
\hline Sample & $\mathrm{C}-\mathrm{C}^{*}$ & $\mathrm{C}-\mathrm{O}$ & $\mathrm{C}=\mathrm{O}$ & $\mathrm{O}-\mathrm{C}=\mathrm{O}$ & CO $_{3}$ & Shake-up \\
\hline Norit Hg-LH & 85 & 3.2 & 0.7 & 1.0 & $\mathbf{1 . 5}$ & 9 \\
Heated Norit LH & 87 & 2.6 & 0.6 & 0.2 & $\mathbf{0 . 2}$ & 9 \\
C5BO 5\% Br & 87 & 2.6 & 1.1 & 0.5 & - & 9 \\
Heated C5BO 5\% Br & 87 & 3.1 & 0.7 & 0.5 & - & 9 \\
C5BR 15\% Br & 87 & 3.4 & 0.9 & 0.2 & - & 9 \\
5\% 80/80 5 days & 81 & 4 & 2 & 2 & $\mathbf{0 . 4}$ & 11 \\
$5 \%$ 80/80 40 days & 79 & 5 & 2 & 2 & - & 12 \\
LH 80/80 40 days & 82 & 3.5 & 2 & 2 & $\mathbf{1 . 5}$ & 9 \\
LH 80/20 275 & 80 & 4 & 2 & 2 & $\mathbf{2}$ & 10 \\
LH 80/80 275 & 80 & 4 & 2 & 3 & $\mathbf{3}$ & 8 \\
LH 120/80 275 & 80 & 4 & 2 & 3 & $\mathbf{2}$ & 9 \\
5\% 80/20 275 & 81 & 4 & 2 & 3 & $\mathbf{1}$ & 10 \\
5\% 80/80 275 & 82 & 4 & 2 & 3 & $\mathbf{0 . 7}$ & 9 \\
5\% 120/80 275 & 82 & 4 & 2 & 3 & $\mathbf{0 . 6}$ & 9 \\
15\% 120/80 275 & 81 & 4 & 2 & 3 & $\mathbf{0 . 7}$ & 9 \\
Darco HgLH T80/RH80 Day 132 & 80 & 4 & 2 & 3 & $\mathbf{2}$ & 9 \\
Darco HgLH T120/RH80 Day 132 & 79 & 4 & 2 & 3 & $\mathbf{2}$ & 10 \\
FGD 5\% Br T80/RH80 Day 132 & 81 & 4 & 2 & 3 & $\mathbf{0 . 8}$ & 10 \\
FGD 5\% Br T120/RH80 Day 132 & 81 & 4 & 2 & 3 & $\mathbf{0 . 8}$ & 9 \\
FGD 5\% HBr - Load & 81 & 4 & 2 & 3 & $\mathbf{0 . 8}$ & 9 \\
\hline
\end{tabular}

* C-H bonding may also contribute to the intensity of this peak. 


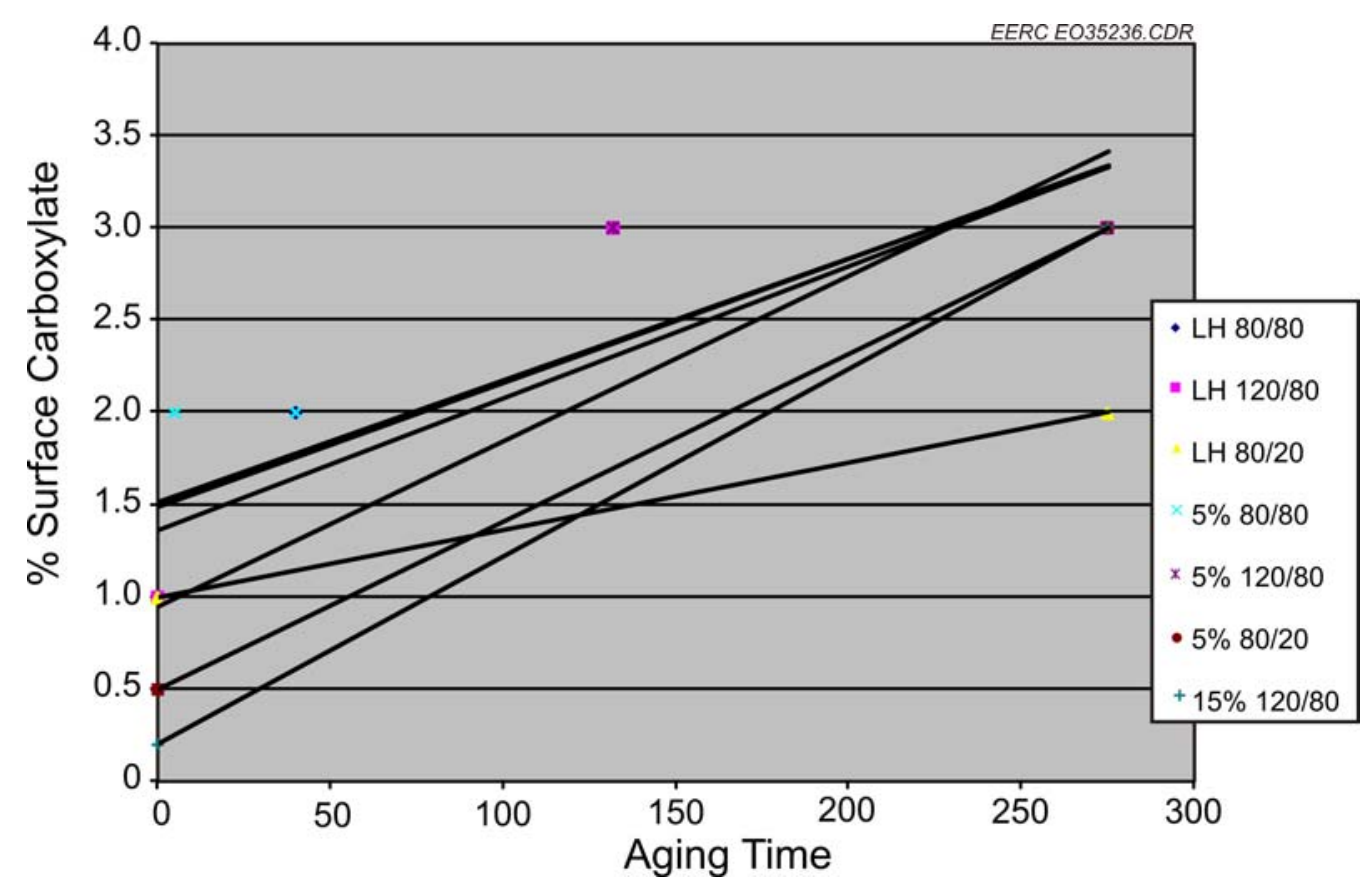

Figure 7. Percentage of surface carboxylate vs. aging time.

\section{Correlation of Carbon Speciation with $50 \%$ Breakthrough}

The lower amount of carboxylate observed for the LH stored at low humidity may explain the difference in the change in breakthrough time observed for this condition. If formation of carboxylate groups is an indication of the loss of edge carbons owing to their reaction with oxygen and moisture over time, the capacity of the carbon will decrease with storage time. Since the oxidation of the LH 80/20 sample was apparently lower, its capacity may have increased with time, owing to other factors, such as increase in $\mathrm{Br}$ or increased oxidation potential from other reactions not studied in this project.

Bromine speciation was investigated using two separate photoelectron energies. Both the $\mathrm{Br} 3 \mathrm{~d}$ and $\mathrm{Br} 3 \mathrm{p}$ spectra indicated that two types of $\mathrm{Br}$ (organobromine and bromide ion) were present in all the samples, which is similar to our previous results with $\mathrm{Cl}$ speciation. $\mathrm{The} \mathrm{Br} 3 \mathrm{~d}$ peaks (actually four component peaks: $3 \mathrm{~d} 3$ organobromine, $3 \mathrm{~d} 5$ organobromine, $3 \mathrm{~d} 3$ bromide, $3 \mathrm{~d} 5$ bromide) are not at all resolved, the two organobromine peaks appearing as a shoulder at $71 \mathrm{eV}$ on the main bromide peaks at $68 \mathrm{eV}$ (Figure 8). The deconvolution program can, however, extract area count information from the $\mathrm{Br} 3 \mathrm{~d}$ composite peak and provide quantitative amounts for the organobromine and bromide species present. The Br 3p spectra are shown in Figure 9. The Br 3p1 peaks for organobromine $(191.0 \mathrm{eV})$ and bromide $(188.5 \mathrm{eV})$ are clearly resolved from the $\mathrm{Br} 3 \mathrm{p} 3$ peaks for organobromine $(184.7 \mathrm{eV})$ and bromide $(181.6 \mathrm{eV})$. Deconvolution of the overlapping $\mathrm{Br} 3 \mathrm{p} 1$ peaks and the overlapping $\mathrm{Br} 3 \mathrm{p} 3$ peaks gave complementary speciation data closely corresponding to that from the $\mathrm{Br} 3 \mathrm{~d}$ peaks. 


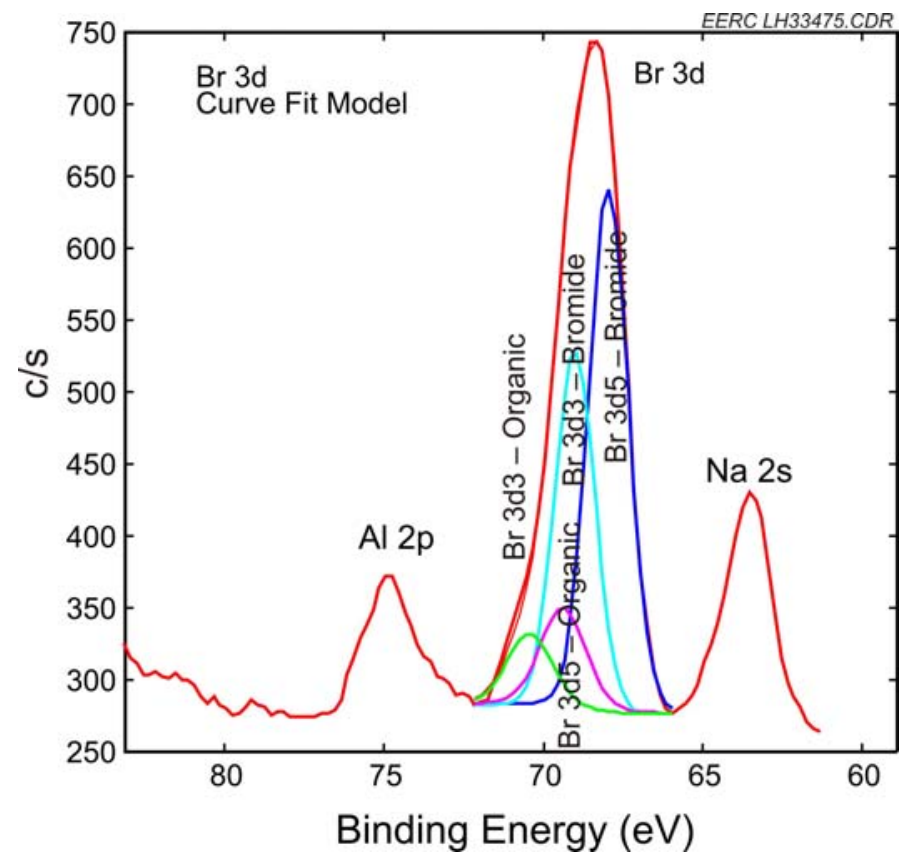

Figure 8. XPS spectra for Norit Hg-LH, Day 0. This shows the deconvolution (full energy level broken into subsets of energies, comprising two organic and two ionic forms). This shows the forms of bromine atoms on the surface of the carbon for the bromine $3 \mathrm{~d}$ only.

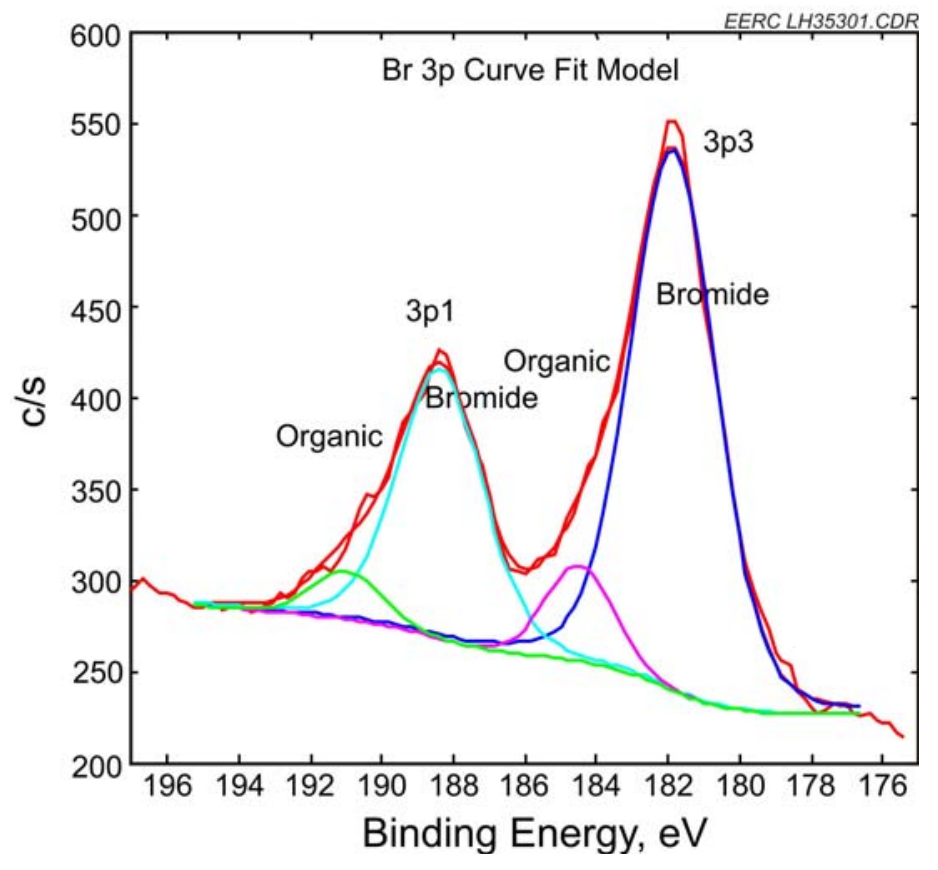

Figure 9 . Br $3 p$ curve fit model. 
Deconvolution data for the $\mathrm{Br} 3 \mathrm{~d}$ spectra obtained for the set of samples are summarized in Table 8. Deconvolution of the $\mathrm{Br} 3 \mathrm{~d}$ peaks of the Day 0 samples indicated that Norit $\mathrm{LH}$ had the most bromide (84\%) and the least organobromine (16\%). The 5\% brominated carbon had $72 \%$ bromide and $28 \%$ organobromine, whereas the $15 \%$ brominated had $62 \%$ bromide and $38 \%$ organobromine.

The Day $5\left(80^{\circ} \mathrm{F} / 80 \% \mathrm{RH}\right)$ sample of the $5 \%$ brominated FGD carbon showed a substantial increase in the bromide concentration to $88 \%$, which persisted in the Day 40 sample, but then decreased to $81 \%$ and $80 \%$ for the final test periods. During storage at $120^{\circ} \mathrm{F} / 80 \% \mathrm{RH}$, the bromide concentration in this carbon increased to similar values over 132 and 275 days. The sample stored at $80^{\circ} \mathrm{F} / 20 \% \mathrm{RH}$ also exhibited a large increase in bromide concentration to $87 \%$ over 275 days, but intermediate points were not taken.

The bromide concentration of the $\mathrm{LH}$ sample stored at $80^{\circ} \mathrm{F} / 80 \% \mathrm{RH}$ increased to $91 \%$ bromide in the 40-day period. Then the sample decreased to its original bromide concentration at 132 and 275 days. Storage at $120^{\circ} \mathrm{F} / 80 \% \mathrm{RH}$ resulted in a small increase in bromide concentration after 132 and 275 days. The sample stored at $80^{\circ} \mathrm{F} / 20 \% \mathrm{RH}$ showed a small decrease in bromide concentration.

Storage of the $15 \%$ brominated sample at $120^{\circ} \mathrm{F} / 80 \% \mathrm{RH}$ for 275 days resulted in the largest increase in bromide concentration. The $81 \%$ bromide concentration was then similar to that obtained for the 5\% brominated sample at Day 275 .

For the $\mathrm{Br} 3 \mathrm{p}$ spectra, deconvolution gave bromide compositions similar to those from the $\mathrm{Br} 3 \mathrm{~d}$ peaks for most of the samples analyzed (Table 9). The increases and decreases in $\mathrm{Br}$ concentrations were parallel to those obtained from the $\mathrm{Br} 3 \mathrm{~d}$, except for the $\mathrm{LH}$ stored at $80^{\circ} \mathrm{F} / 80 \% \mathrm{RH}$ where the bromide concentration at 132 days and 275 days stayed high instead of dropping.

Table 8. Bromine Surface Chemistries for Brominated Samples (\% bromide from XPS Br 3d deconvolution for each temperature/humidity storage condition for each sorbent)

\begin{tabular}{l|ccc|ccc|c}
\hline & \multicolumn{3}{|c|}{ LH } & \multicolumn{3}{c|}{$5 \%$} & $15 \%$ \\
\hline Day & $80 / 80$ & $120 / 80$ & $80 / 20$ & $80 / 80$ & $120 / 80$ & $80 / 20$ & $120 / 80$ \\
0 & 84 & 84 & 84 & 72 & 72 & 72 & 62 \\
5 & & & & 88 & & & \\
40 & 91 & & & 90 & & & \\
132 & 84 & 86 & & 81 & 83 & & \\
275 & 83 & 89 & 81 & 80 & 78 & 87 & 81 \\
\hline
\end{tabular}




Table 9. Bromine Surface Chemistries for Brominated Samples (\% bromide
from XPS Br 3p deconvolution for each temperature/humidity storage
condition for each sorbent)
\begin{tabular}{l|ccc|ccc|c}
\hline & \multicolumn{3}{|c|}{ LH } & \multicolumn{3}{c}{$5 \%$} & $15 \%$ \\
\hline Day & $80 / 80$ & $120 / 80$ & $80 / 20$ & $80 / 80$ & $120 / 80$ & $80 / 20$ & $120 / 80$ \\
\hline 0 & 84 & 84 & 84 & 72 & 72 & 72 & 62 \\
5 & & & & 89 & & & \\
40 & 92 & & & 89 & & & \\
132 & 87 & 85 & & 78 & 84 & & \\
275 & 90 & 83 & 84 & 83 & 80 & 86 & 84 \\
\hline
\end{tabular}

In summary, the bromide concentrations of the EERC brominated FGD samples increased after storage under the high humidity conditions, but decreased in low humidity. The concentrations of the LH samples stayed about the same. The plots of \% bromide (from the $\mathrm{Br} 3 \mathrm{p}$ and $\mathrm{Br} 3 \mathrm{~d}$ lines) versus aging time are shown in Figures 10 and 11, respectively. The severity of the storage condition did not seem to be a factor in determining the bromide concentration for the LH carbon.

\section{Correlation of Bromine Speciation Results with Mercury Capacity}

Plots of the $50 \%$ breakthrough times versus the $\%$ bromide (from the $\mathrm{Br} 3 \mathrm{~d}$ line) in the various samples are shown in Figure 12. Generally, the slopes are negative, but relatively small. The problem in explaining a bromide effect is that we do not know what cation the bromide is associated with. Bromide by itself is not an oxidant for mercury, but it may be indicative of formation of a carbenium ion, which could be an oxidant.

\section{Heated Samples}

Heating increased the surface $\mathrm{Br}$ in the $\mathrm{LH}$ considerably, but not in the $5 \%$. We offer no explanation. It is unlikely any $\mathrm{Br}$ was lost from the sample.

Oxygen concentrations dropped by one-third in the heated samples, owing to loss of water and carbonate from the carbons. Carbon concentration increased for the same reason.

Heating the Norit resulted in low carboxylate and carbonate from loss of $\mathrm{CO}_{2}$.

Heating the $5 \%$ bromine sample showed no change in the bromine speciation. In contrast, the heated LH gave a significantly different spectrum. This appeared to result from a conversion of bromide to mainly organobromine form. Deconvolution results gave $75 \%$ organobromine and $25 \%$ bromide for the heated LH. 


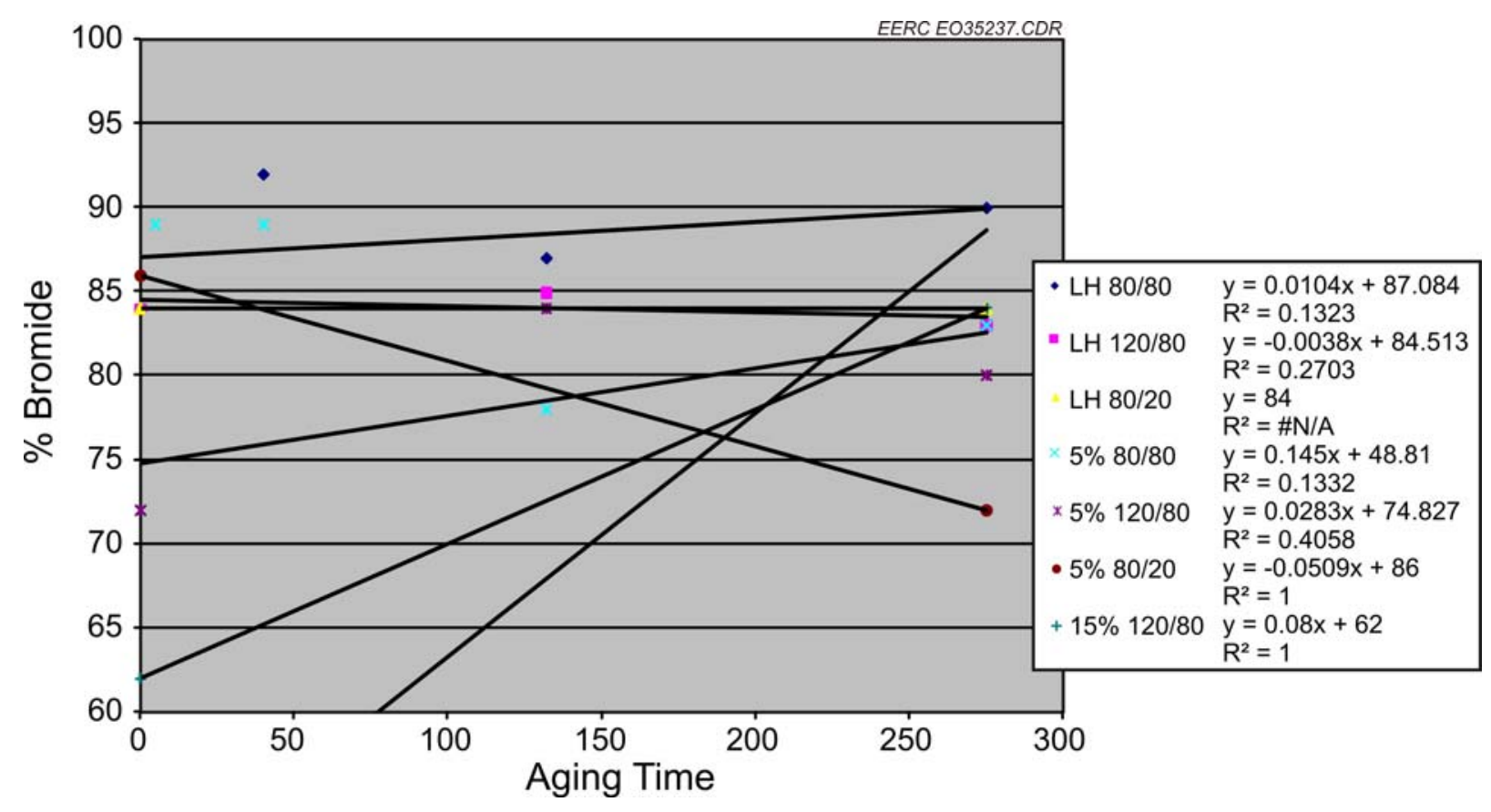

Figure 10. Percent bromide $(\mathrm{Br} 3 p)$ vs. aging time.

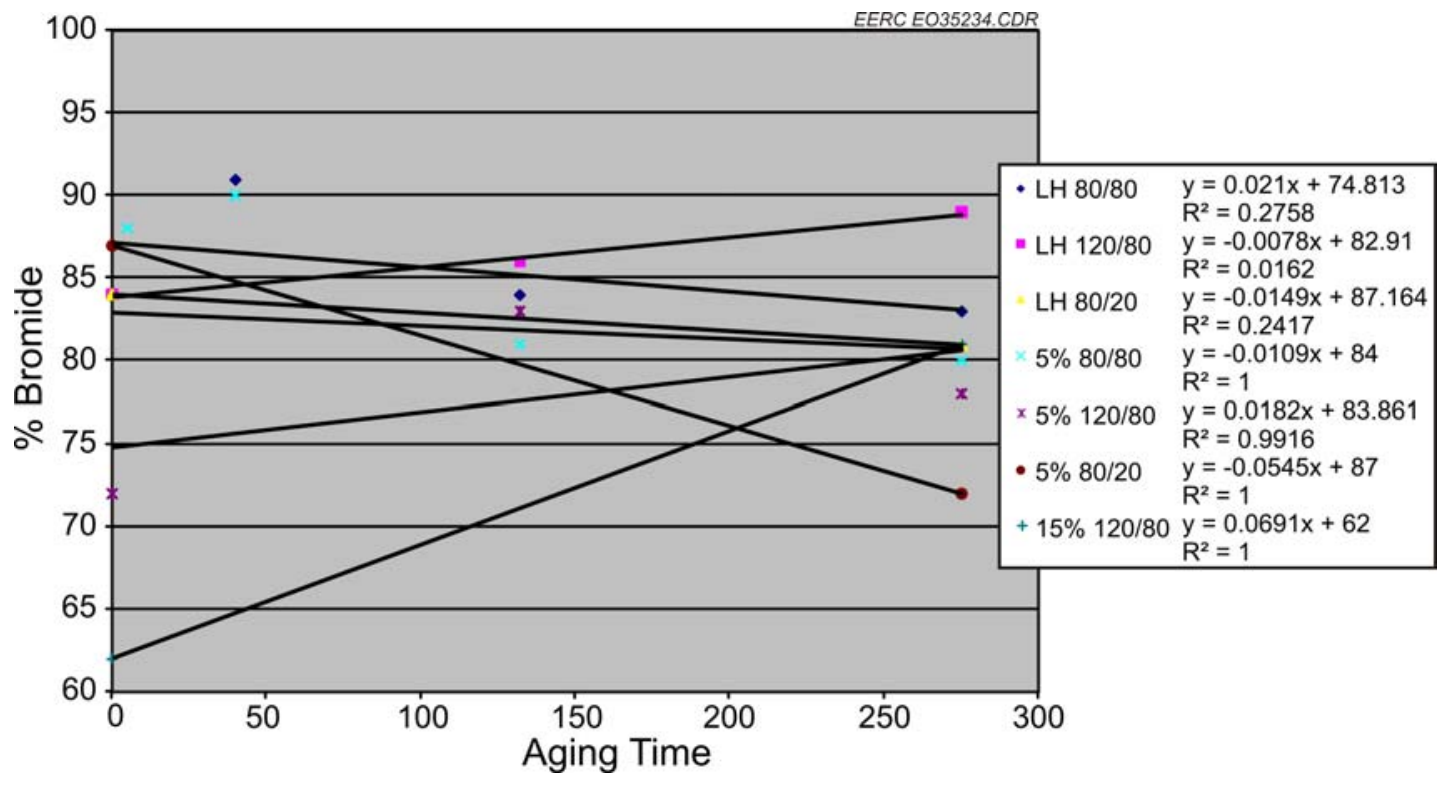

Figure 11. Percent bromide ( $\mathrm{Br} 3 \mathrm{~d})$ vs. aging time. 


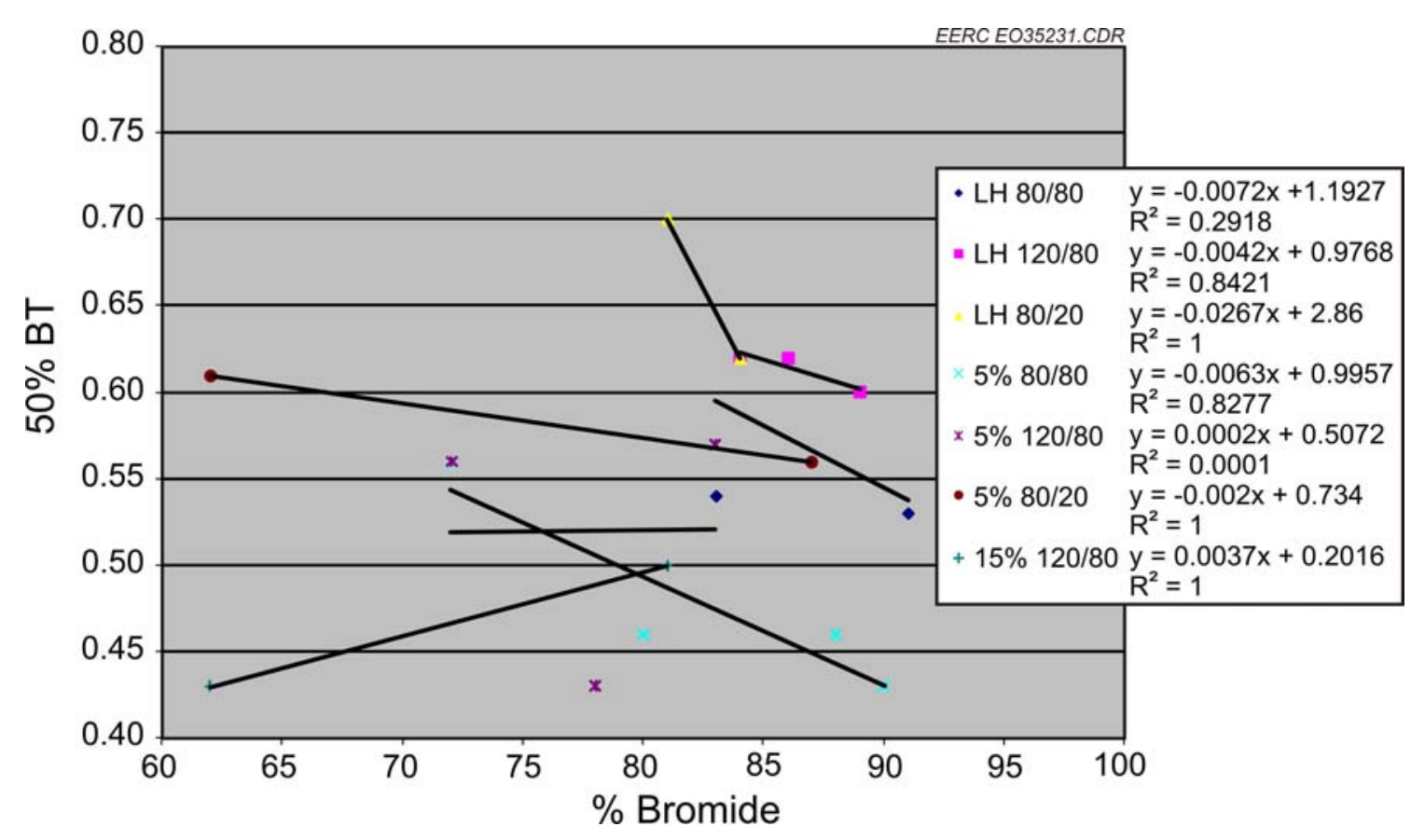

Figure $12.50 \%$ breakthrough vs. $\%$ bromide.

\section{Sample Analysis Using XAFS}

\section{XANES}

The x-ray absorption near-edge structure (XANES) spectra of all samples were exceptionally high quality (low noise) spectra. The spectra of the samples stored for various times were generally very similar, but differed substantially from the initial samples. Hutson et al. (2009) also showed XANES spectra of Norit LH and BPAC, but were unable to offer any information on the bromine structural features. Some earlier studies were done in Japan with brominated high-temperature carbon samples that were subsequently heated in a vacuum. These spectra are quite different and probably not applicable to the activated carbon samples.

At Day 0 , the XANES spectra of the $5 \% \mathrm{Br}$ and the LH were similar, but not identical (Figure 13 and Table 10). The 5\% bromine sample spectrum had a distinct "preedge peak" or shoulder at 13,471 eV. The maximum intensity edge peak for both samples was $13,477 \mathrm{eV}$. The maximum intensities were not the same, but the intensity is not a reliable feature of the spectrum. The LH edge peak was substantially broader and rounder, however, indicating that there were a larger range of bromine species present in the sample.

For example, more ionic bromide present in the LH peak, as determined by the XPS spectral results, would contribute more intensity to the higher energy portion of the XANES peak for the LH. The LH spectrum lacked any trace of the preedge peak. The origin of this peak is yet unknown, but may represent the $1 \mathrm{~s} \rightarrow \varsigma^{*}$ transition for a bromine compound. 


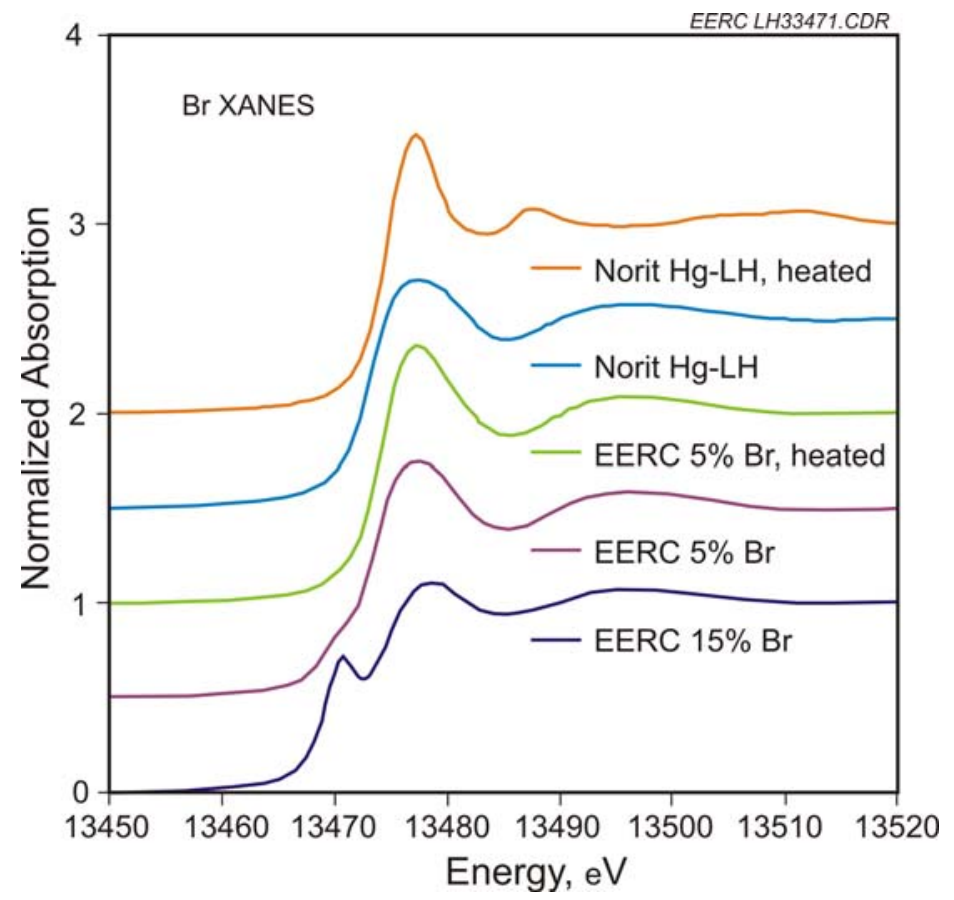

Figure 13. Spectra data for five brominated activated carbons, Day 0. Samples are shown above one another rather than overlaying one another in order to clearly view the separate peaks.

The Day $015 \%$ Br sample exhibited a very large preedge peak at 13,471 eV and the edge peak at 13,479 . The peak shape was somewhat broader like the LH sample.

Under most of the storage conditions, essentially no changes were observed in the XANES spectra of the LH sorbent (Figures 14 and 15) The rounder broader peak with an edge peak maximum at 13,477 eV was obtained for the Day 40 80/80, the Day 275 80/20, and Day 275 $80 / 80$ conditions. The exception was LH sample stored 275 days at $120 / 80$ conditions, where a sharper peak was observed at $13,477 \mathrm{eV}$.

In contrast, the 5\% $\mathrm{Br}$ sample XANES spectrum changed significantly in the 40-day storage period under $80 / 80$ conditions, with the loss of the preedge shoulder and a change in peak shape to the rounder broader form, but no change in the edge peak energy was found. No further change occurred in the spectrum on storage for 275 days at the 80/80,120/80, and 80/20 conditions The XANES spectra for all the 5\% stored samples were, therefore, identical to those of the LH stored samples.

The XANES spectrum of the 15\% Br sample at Day $275(120 / 80)$ showed only a very small shoulder corresponding to the preedge peak at $13,470 \mathrm{eV}$. The edge peak was at $13,477 \mathrm{eV}$. The peak shape after 275 days of storage $(120 / 80)$ was narrowed and resembled the LH 120/80 spectrum except for the very small shoulder. 


\begin{tabular}{|c|c|c|c|c|c|c|c|c|}
\hline \multirow[t]{2}{*}{ Sample } & \multirow[t]{2}{*}{$\begin{array}{c}\text { Storage } \\
\text { Days }\end{array}$} & \multicolumn{2}{|c|}{ XANES eV } & \multicolumn{5}{|c|}{ EXAFS-radial structure function a.u. } \\
\hline & & Edge & Preedge & $1.2 \AA$ & $1.5 \AA$ & $1.8 \AA$ & $2.2 \AA$ & $2.7 \AA$ \\
\hline Norit LH & 0 & $\begin{array}{r}13,477 \\
\text { broad }\end{array}$ & none & - & - & - & - & - \\
\hline $\begin{array}{l}\text { Norit LH } \\
80 / 80\end{array}$ & 40 & $\begin{array}{c}13,478 \\
\text { broad }\end{array}$ & none & 0.75 & $\mathrm{sh}$ & 0.50 & 0.78 & 0.80 \\
\hline $\begin{array}{c}\text { Norit LH } \\
80 / 20\end{array}$ & 275 & $\begin{array}{r}13,477 \\
\text { broad }\end{array}$ & none & 0.91 & $\mathrm{sh}$ & 0.54 & 0.83 & .79 \\
\hline $\begin{array}{c}\text { Norit LH } \\
80 / 80\end{array}$ & 275 & $\begin{array}{r}13,477 \\
\text { broad }\end{array}$ & none & 0.91 & $\mathrm{sh}$ & 0.54 & 0.85 & 0.82 \\
\hline $\begin{array}{c}\text { Norit LH } \\
120 / 80\end{array}$ & 275 & 13,477 & none & 0.91 & $\mathrm{sh}$ & 0.54 & 0.36 & 0.36 \\
\hline EERC 5\% Br FGD & 0 & 13,477 & $\begin{array}{c}13,471 \\
\text { sh }\end{array}$ & 0.86 & 0 & 0.52 & 0.80 & 0.61 \\
\hline $\begin{array}{l}\text { EERC 5\% Br FGD } \\
\quad 80 / 80\end{array}$ & 40 & $\begin{array}{c}13,478 \\
\text { broad }\end{array}$ & none & 0.75 & $\mathrm{sh}$ & 0.55 & 0.92 & 0.90 \\
\hline $\begin{array}{l}\text { EERC 5\% Br FGD } \\
\quad 80 / 20\end{array}$ & 275 & $\begin{array}{r}13,477 \\
\text { broad }\end{array}$ & none & 0.91 & $\mathrm{sh}$ & 0.48 & 0.82 & 0.79 \\
\hline $\begin{array}{l}\text { EERC 5\% Br FGD } \\
\quad 80 / 80\end{array}$ & 275 & 13,477 & none & 0.79 & $\mathrm{sh}$ & 0.48 & 0.82 & 0.86 \\
\hline $\begin{array}{l}\text { EERC 5\% Br FGD } \\
\quad 120 / 80\end{array}$ & 275 & 13,477 & none & 0.85 & $\mathrm{sh}$ & 0.53 & 0.85 & 0.79 \\
\hline EERC $15 \%$ Br FGD & 0 & 13,478 & $\begin{array}{c}13,471 \\
\text { large }\end{array}$ & - & - & - & - & - \\
\hline $\begin{array}{l}\text { EERC 15\% Br FGD } \\
120 / 80\end{array}$ & 275 & 13,477 & $\begin{array}{c}13,471 \\
\text { sh }\end{array}$ & 0.88 & $\mathrm{sh}$ & 0.15 & 1.00 & $\mathrm{sh}$ \\
\hline
\end{tabular}




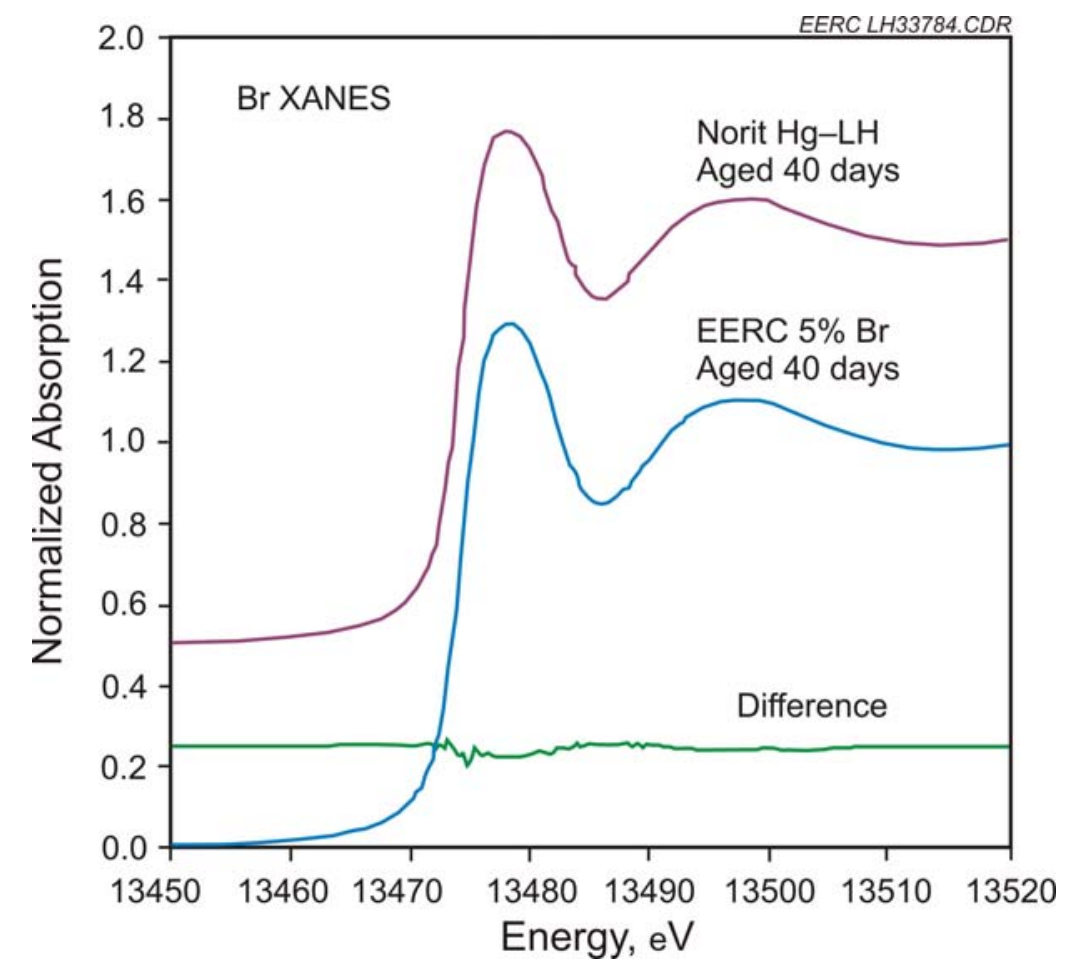

Figure 14. XANES of Day 40 aged samples.

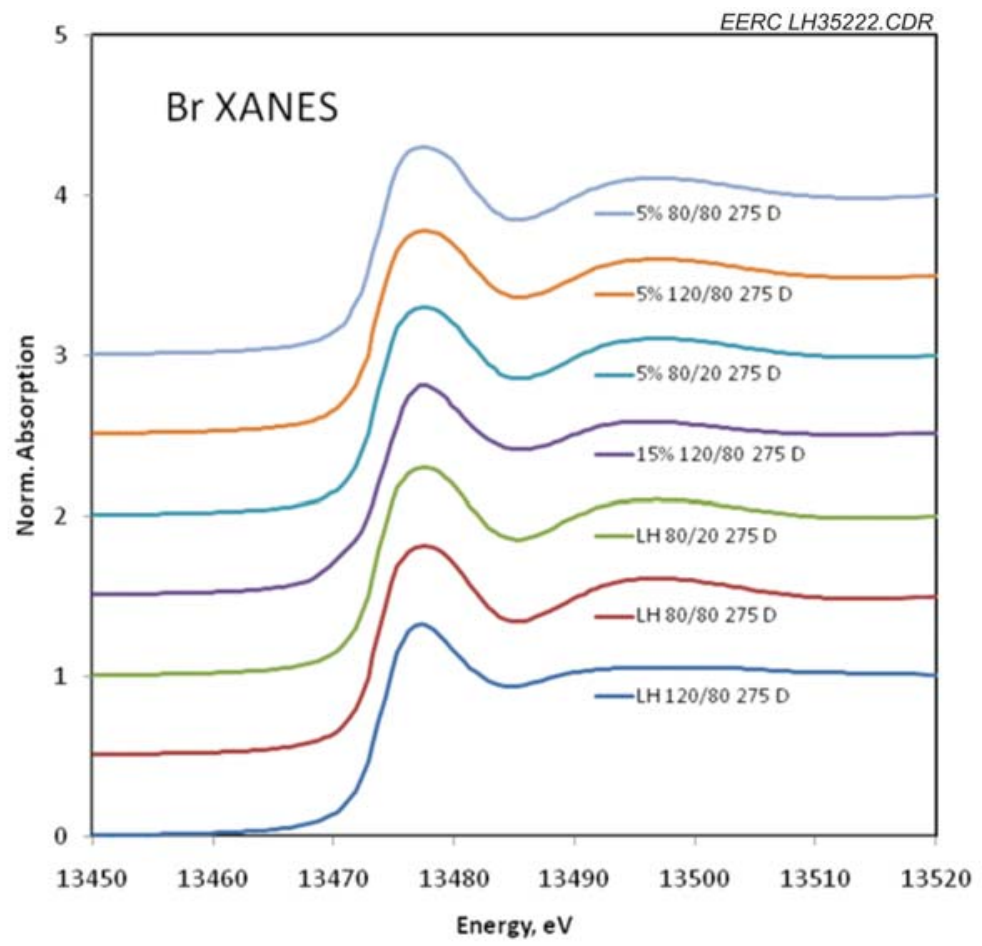

Figure 15. XANES for Day 275 samples. 


\section{EXAFS}

The Fourier transformed spectrum (EXAFS/RSF) for the 5\% brominated carbon showed highly resolved peaks corresponding to backscattering of the photoelectron between a bromine and each of its nearest neighbors, whose distances from the bromine are related to the RSF plot (Figure 16). The initial or Day 0 bromine EXAFS-RSF spectra were obtained only for the 5\% brominated sample. This spectrum and the storage sample spectra for this carbon were very good quality spectra. The beam was operating with higher x-ray flux, whereas spectra for the other two initial carbon samples were of borderline quality. This truly exceptional spectral information will be valuable in understanding changes that occur with aging. Thus the nearest atoms at $1.25,1.8,2.2$, and $2.6 \AA$ were indicated. Clearly, there is no Br bond at this short length, so what is wrong is that the data are uncorrected for a phase shift that occurs in association with the backscattering process. We do not have a straightforward relationship between bond length and the RSF plot; however, by comparison to various organobromine standards, structural features can be deduced using a modeling approach. The $1.25 \AA$ RSF peak corresponds to a bromine directly bonded to carbon with a bond length of $1.85 \AA$. The subsequent peaks correspond to backscattering interactions of the bromine with more distant carbons and bromines. In the discussion below, the RSF values are given, rather than the true bond lengths. These distances are illustrated in Figures 17 and 18.

The EXAFS of the $5 \% \mathrm{Br}$ sample at 40 days (80/80 conditions) was slightly different from the Day 0 spectrum (Figure 16). The Day 40 sample contained a shoulder at $1.5 \AA$, not seen in the Day 0 spectrum, as well as a significant lowering in intensity of the $1.2 \AA$ peak relative to the 2.2 and $2.7 \AA$ peaks. The EXAFS spectra obtained from the 5\% Br samples from Day 275 $120 / 80,80 / 80$, and 80/20 were all identical to the Day 40 spectrum, including the $1.5 \AA$ shoulder (Figure 19).

The additional shoulder in the EXAFS at $1.5 \AA$ in the $5 \%$ Br sample on storage shows that some portion of the $\mathrm{Br}$ atoms have moved to a longer nearest atom $\mathrm{Br}$ distance (about $0.4 \AA$ ). It is, of course, not clear whether this corresponds to bonding to a different atom or the same atom, but with a much weaker bond strength, corresponding to a much longer bond length. The shift might be consistent with hydrolysis reactions, resulting in conversion of edge-bound bromines to coordinated bromides, as represented in Figure 18. Since the spectrum does not change on further storage of the $5 \%$ bromine sample, the reactions likely reach some equilibrium position, where further hydrolysis is not observed. The relationship of the change in the EXAFS to the disappearance of the preedge peak in the XANES is not clear. They are likely not related.

The EXAFS of LH and 5\% Br samples were almost identical at Day 40 (Figure 19). The relative peak intensities of the 2.2 and $2.7 \AA$ peaks were somewhat lower for the LH sample. The spectra (Figure 20) of the LH samples stored for 275 days at 80/80 and 80/20 also were identical to the Day 40 spectrum (Figure 19). But the sample stored for 275 days at 120/80 showed considerable deviation. The same peaks were present, but the intensities of the 2.2 and $2.6 \AA$ peaks were relatively low. 


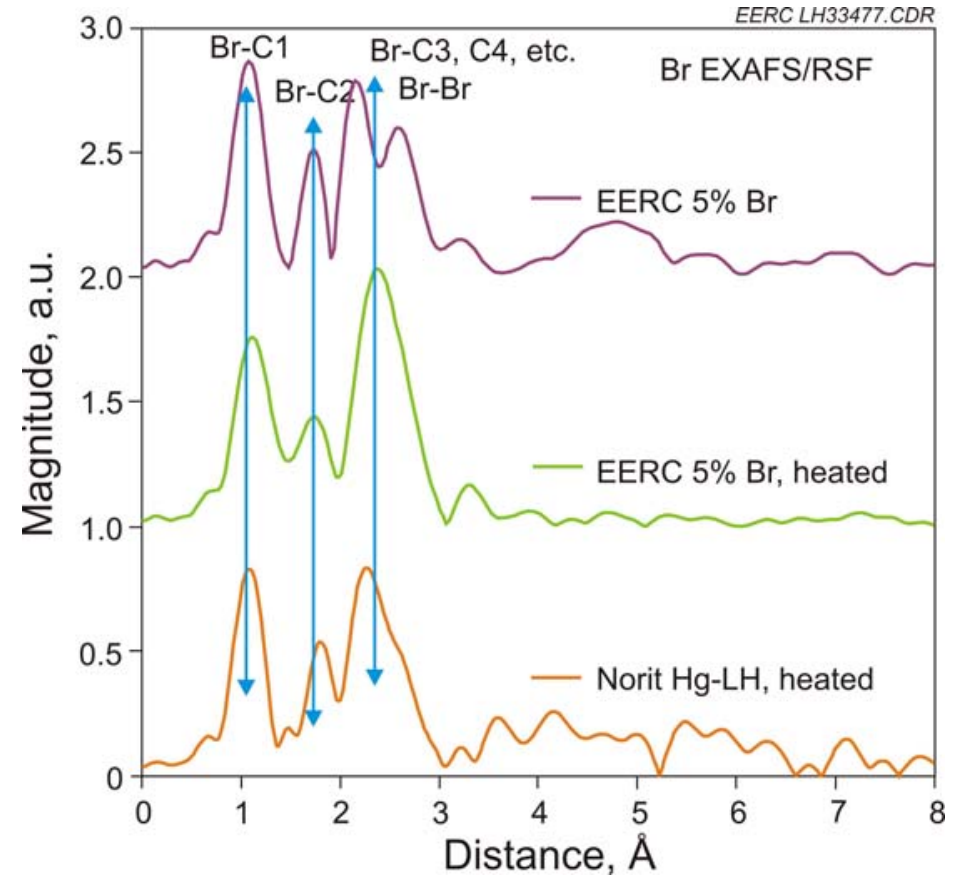

Figure 16. EXAFS/RSF data for Day 0 sample and heated samples.

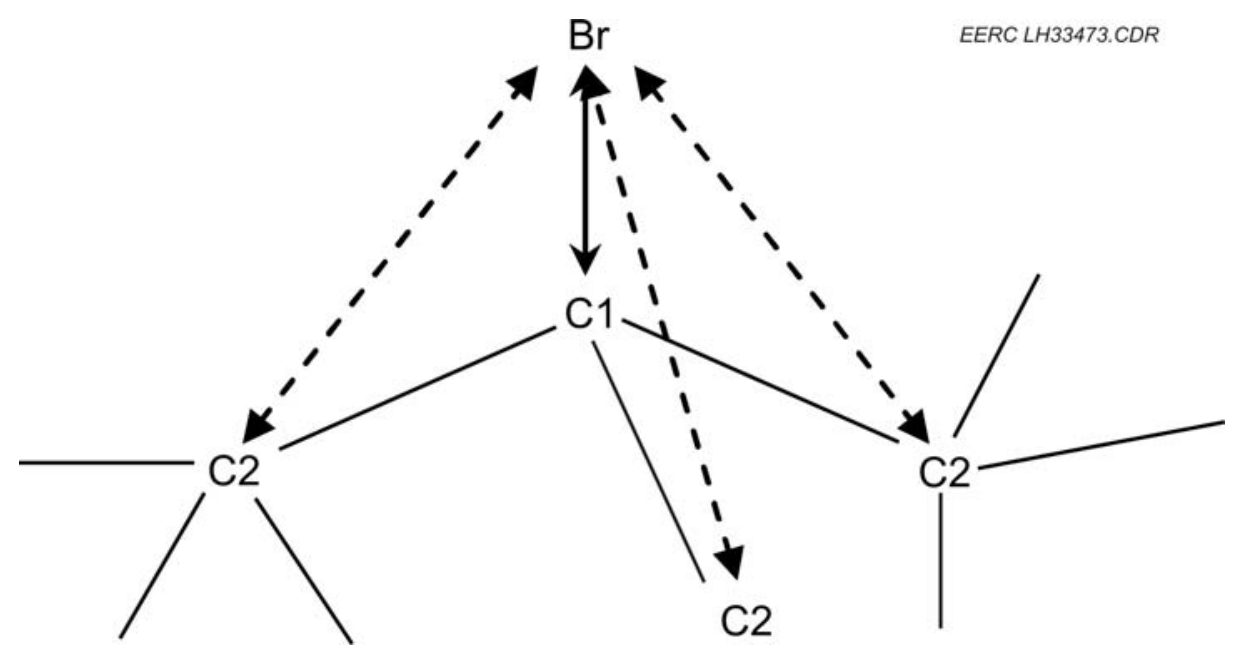

Figure 17. The bromine-carbon structure that is determined from the first two peaks of the EXAFS/RSF data produced by Dr. Huggins. 


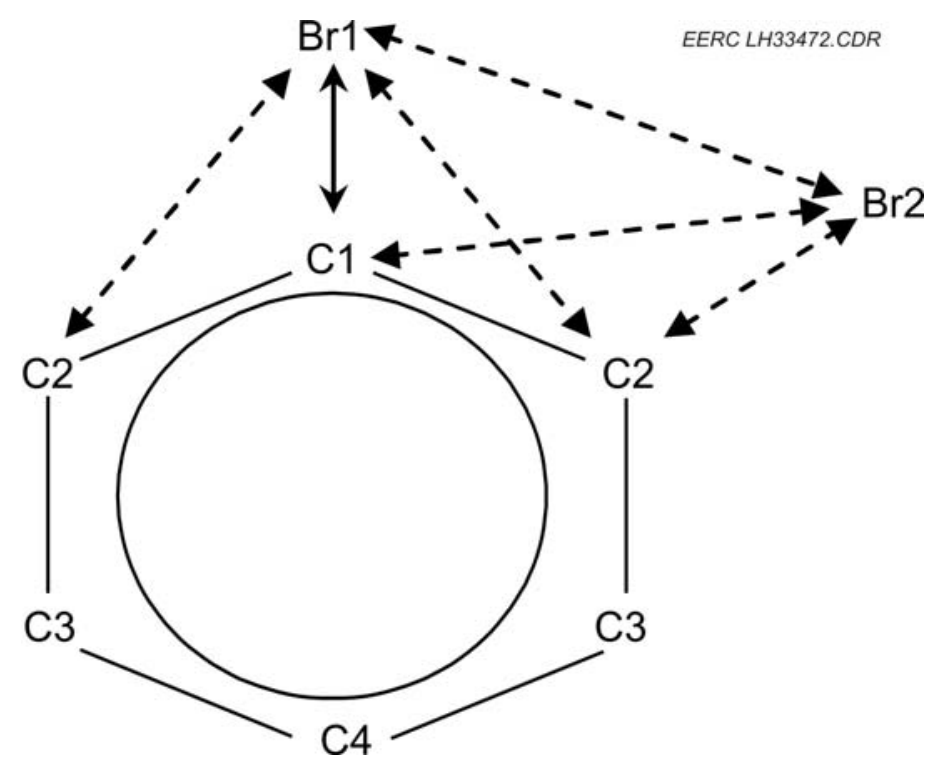

Figure 18. The bromine-carbon structure is further defined by looking at the third EXAFS peak, suggesting that the bromine atoms are bound to a rigid structure, possibly a benzene ring.

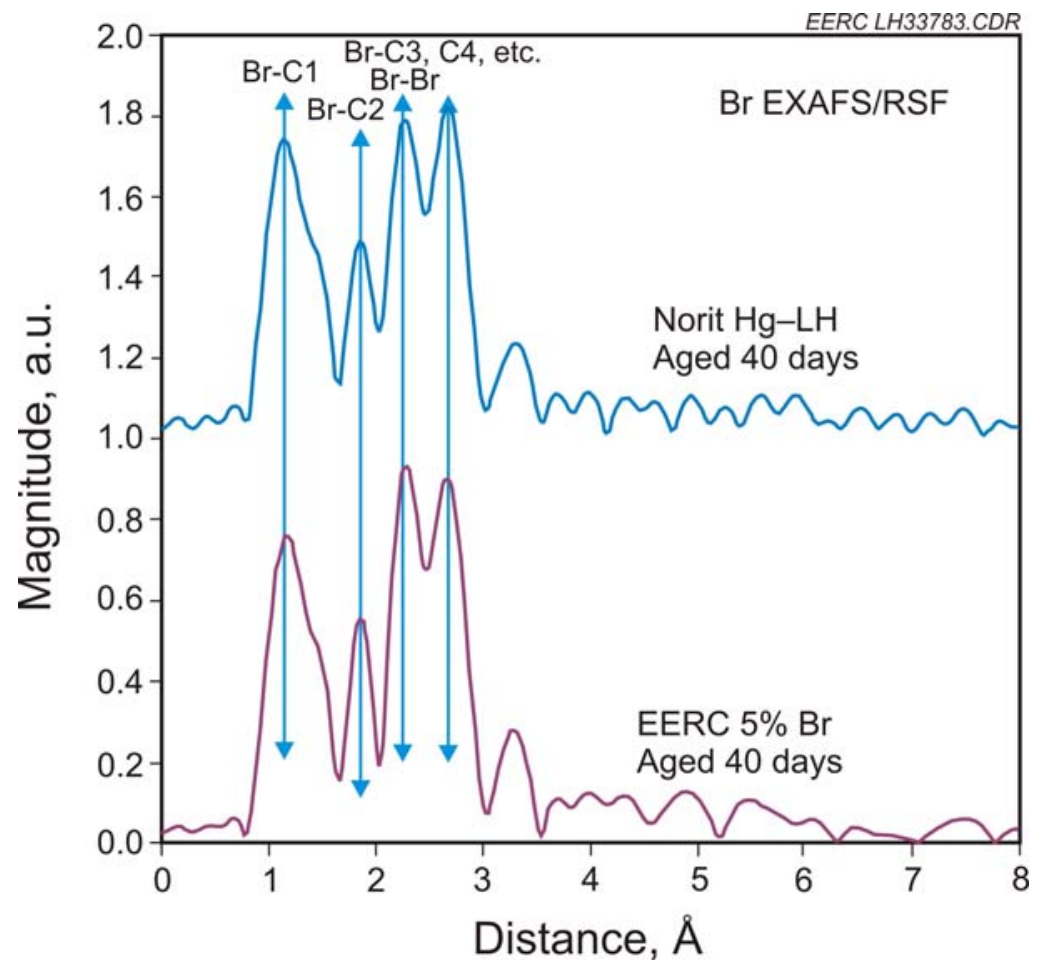

Figure 19. EXAFS of Day 40 samples (compare to Figure 4 for Day 0). 


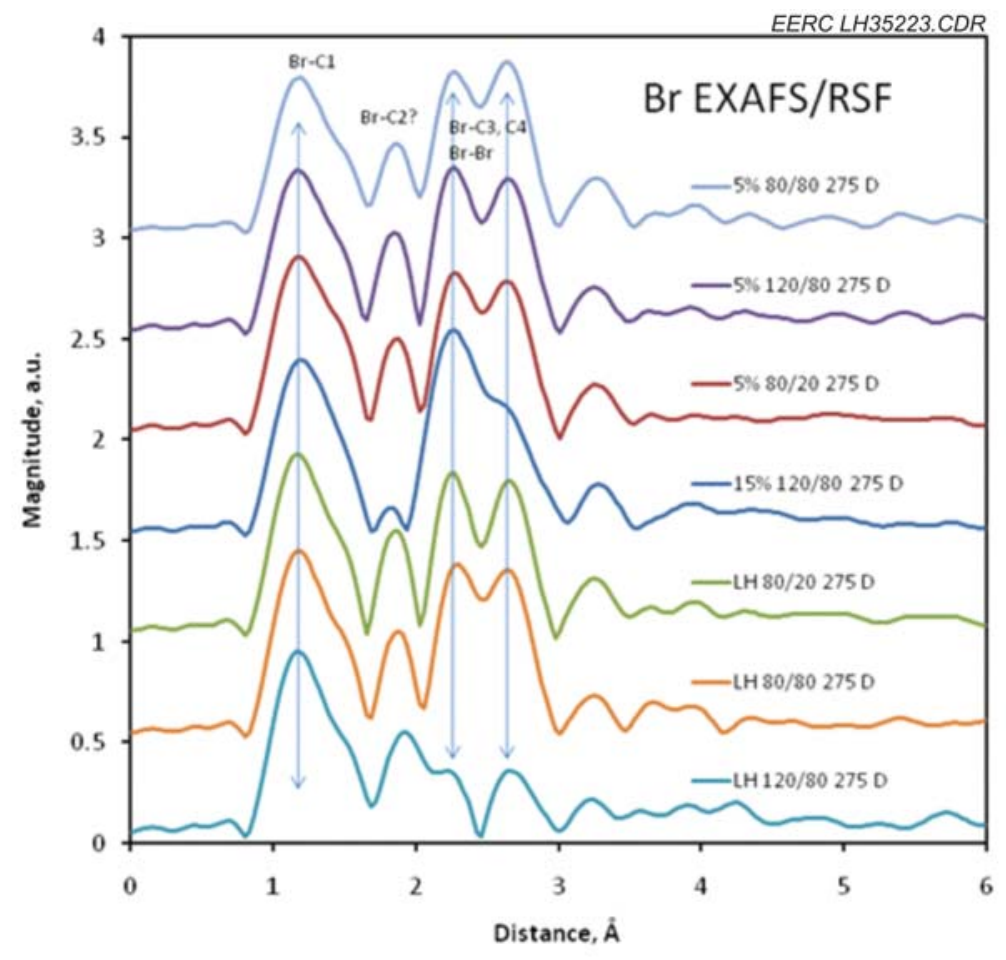

Figure 20. EXAFS of Day 75 samples.

The EXAFS of the $15 \% \mathrm{Br}$ sample stored for 275 days at $120 / 80$ showed the same peaks as the other samples, but the relative intensities of the peaks varied. The $2.2 \AA$ peak was considerably larger than the other peaks, and the $1.8 \AA$ A peak was relatively small. Unfortunately, we do not have a good Day 0 spectrum for comparison.

\section{CONCLUSIONS}

Test results to evaluate the effect of storage time on the change in mercury capture effectiveness show that, overall, the effect of aging under most conditions has a negligible effect on the initial capture reactivity of ACs. No aging effects on initial capture activity were observed for any carbons or conditions in the investigation.

As measured by the $50 \%$ breakthrough time, no changes in capacity were observed for Norit LH samples stored frozen and likely none for Norit LH samples stored under high humidity conditions. It is likely that small decreases observed in some experiments conducted at high humidity resulted from uneven beds of the stickier samples. The EERC 5\% brominated samples showed a decrease in capacity during the first week of storage under high humidity conditions. Storage of the Norit LH and the EERC 5\% brominated samples under low humidity conditions resulted in slightly improved capacities. Storage of the $15 \%$ brominated sample under high humidity conditions also improved the capacity. 
Surface analysis using XPS showed some migration of bromine to and from the surface occurred during storage, although no net loss of bromine was observed. The migration to the surface in the case of the $15 \%$ brominated carbon correlates with the increased capacity observed for this sample. The XPS elemental speciation data for the EERC brominated carbons showed a trend toward more bromide being formed at the expense of covalent bromine during storage. This was especially great for the $15 \%$ and the $5 \%$ stored in low humidity. The Norit LH samples did not show this increase in bromide concentration. This is consistent with the lack of change in capacity for the Norit LH during storage. The carbon speciation data showed generally more oxidization of carbon surfaces with storage, especially formation of carboxylate groups. The least increase in carboxylate groups was seen for the Norit LH stored under low humidity, which correlates with its increased capacity. In conclusion, the observed changes in surface chemistry can be related to the minimal changes in capacity observed, but the factors operate in different directions, so the relationships are complex.

High-quality XAFS spectra were obtained for most of the samples. Significant changes were observed in the XANES and EXAFS spectra of the stored carbons, but proved difficult to interpret and correlate with structural changes.

Outcomes of this project will also be useful in the ongoing development of a predictive AC model that was developed at the EERC (10) to explain interactions with various flue gas constituents; this model continues to serve as a predictive tool for $\mathrm{AC}$ injection.

\section{REFERENCES}

1. Jones, A.P.; Hoffmann, J.W.; Smith, D.N.; Feeley, T.J. III; Murphy, J.T. DOE/NETL's Phase II Mercury Control Technology Field Testing Program: Preliminary Economic Analysis of Activated Carbon Injection; Report for U.S. Department of Energy Office of Fossil Energy National Energy Technology Laboratory Innovations for Existing Plants Program; April 2006.

2. Pavlish, J.H.; Sondreal, E.A.; Mann, M.D.; Olson, E.S.; Galbreath, K.C.; Laudal, D.L.; Benson, S.A. A Status Review of Mercury Control Options for Coal-Fired Power Plants. Special Mercury Issue of Fuel Process. Technol. 2003, 82 (2-3), 89-165.

3. Pavlish, J.H.; Hamre, L.L.; Laudal, D.L.; Holmes, M.J.; Weber, G.F.; Hajicek, D.R.; Pavlish, B.M. Technical Review of Mercury Options for Canadian Utilities - A Report to the Canadian Council of Ministers of the Environment; Final Report to the Canadian Council of Ministers of the Environment; Contract No. 348-2005; EERC Publication 2005-EERC-0307; Energy \& Environmental Research Center: Grand Forks, ND, March 2005.

4. Pavlish, J.H.; Thompson, J.S.; Almlie, J.C.; Hamre, L.L.; Musich, M.A.; Heebink, L.V.; Crocker, C.R.; Olson, E.S. Mercury Control Technologies for Electric Utilities Burning Lignite Coal - Phase II; Final Report (June 1, 2003 - Dec 31, 2007) for U.S. Department of Energy National Energy Technology Laboratory Cooperative Agreement No. DE-FC2698FT40321; Energy \& Environmental Research Center: Grand Forks, ND, March 2007. 
5. Holmes, M.J.; Wocken, C.A.; Thompson, J.S.; Pavlish, J.H.; Martin, C.L.; Eriksen, B.; McDonald, D.; Brickett, L.A. Mercury Control Test Results for Western Coals - Activated Carbons and Sorbent Enhancement Additives. In Proceedings of the Power-Gen International 2005 Conference; Las Vegas, NV, Dec 6-8, 2005.

6. Thompson, J.S.; Pavlish, J.H.; Holmes, M.J.; Bush, C. Enhancing Carbon Reactivity for Mercury Control: Field Test Results from Leland Olds. Abstract for the EPRI-EPAA\&WMA Power Plant Air Pollutant Control "Mega" Symposium, Washington, DC, Aug 30 - Sept 2, 2004.

7. Pavlish, J.H.; Holmes, M.J.; Benson, S.A.; Crocker, C.R.; Olson, E.S.; Galbreath, K.C.; Zhuang, Y.; Pavlish, B.M. Mercury Control Technologies for Electric Utilities Burning Lignite Coal, Phase 1 Bench- and Pilot-Scale Testing; Final Report (Feb 1 - March 31, 2003) for U.S. Department of Energy National Energy Technology Laboratory Cooperative Agreement No. DE-FC26-98FT40321; EERC Publication 2003-EERC-10-03; Energy \& Environmental Research Center: Grand Forks, ND, Oct 2003.

8. Sjostrom, S.M.; Wilson, C. Full-Scale Evaluation of Carbon Injection for Mercury Control at a Unit Firing High Sulfur Coal. Presented at the Mercury Control Technology R\&D Program Review Meeting, Pittsburgh, PA, Dec 11-13, 2006.

9. Hutson, N.D.; Attwood, B.C.; Scheckel, K.G. XAS and XPS Characterization of Mercury Binding on Brominated Activated Carbon. Envron. Sci. Technol. 2007, 41, 1747-1752

10. Olson, E.S.; Laumb, J.D.; Benson, S.A.; Dunham, G.E.; Sharma, R.K.; Mibeck, B.A.; Miller, S.J.; Holmes, M.J.; Pavlish, J.H. An Improved Model for Flue Gas-Mercury Interactions on Activated Carbons. Presented at the DOE-EPRI-EPA-A\&WMA Power Plant Air Pollutant Control "Mega" Symposium, Washington, DC, May 19-22, 2003. 